\title{
Behaviour of some olive accessions resulting from an olive improvement program
}

\author{
Emad Girgis Mikhail \\ Olive and Fruits of Semi Arid Zone Dep., Hort. Res. Inst., ARC,EGYPT
}

\begin{abstract}
The olive (Olea europaea) is one of the most important oleaginous crops of the Mediterranean basin. Increased demand for olive oil creates a need for new olive varieties to help meet the requirements of the global market. Rapid technological changes in olive growing have increased interest in breeding programs and new cultivars. A breeding program aimed at selecting new dual purpose (i.e. oil and table olive) cultivars, began in Egypt in 1994.

A three successive years evolution (2011, 2012 and 2013) was conducted on progenies resulted from crosses between (Koronaki x Hamed), (Manzanello x Hamed) (Picual x Hamed) and (Arbquine x Hamed). The progenies have been analyzed for some tree growth traits, growth, blooming, fruiting, fruit quality and rootability. The obtained data, concluded that some valuable selections have resulted from this study progenies No. 73, 91 and 100 for table olive, whereas progenies No. 42, 47, 71, 89 and 98 for oil besides, progenies No. 57 and 59 for dual purpose.

Thereupon, it is preferable to propagate all the best selected progenies and planted in three locations, in order to evaluate their performance (i.e., tree growth, yield, fruit characteristics, oil content and oil compositions in fatty acids) in different geographical areas. It remains necessary to study quantities and qualitative traits of olive production in more detail, for the most interesting selections.
\end{abstract}

Key words: Olive, Progenies, Table olive, Oil olive, Cross breeding, Aggizi, Chemlali, Kalamata, Koroneiki.

\section{Introduction}

It is possible to enlarge the natural genetic variability of the olive through the cross breeding technique in which searching for interesting genotypes is aimed (Bellini et al., 2002).

Bellini et al., (2008) found that the origin and phylogenesis of olive (Olea europaea L.) remain unclear. The olive's early domestication and the use of vegetative propagation have resulted in the development of a huge number of varieties. Olive breeding has been achieved both by clonal selection and by cross-breeding. Clonal selection has been widely adopted and has been utilized for morphological characterization. The olive industry is seeking new cultivars better suited to modern cultivation techniques.

In this concern, any genetic improvement program by cross breeding will need strong efforts and long time to obtain next generation besides its agronomical evaluation in the field. Juvenility period has been traditionally one of the main detects of fruit tree breeding including olive. However, in the last years, several methodologies aimed at shortening the length of the juvenile period have been approached, thus facilitating the progress of the breeding process. (Lavee et al., 1996 and Santos-Antunes et al., 1999). This has promoted the developmental process of olive breeding programs in the main olive producing countries (Leon et al., 2006).

Muzzalupo and Perri (2009) mentioned that Olive (Olea europaea L.) was one of the first plants to be cultivated for virgin olive oil and for olive table production. The genotyping of cultivated varieties using molecular markers is a crucial aim of modern plant breeding programmes and germplasm collection management.

Few breeding programs of olive by crossing and selection in the progenies have been initiated in the past decades (Lavee, 1990; Bellini, 1992; Arsel and Cirik, 1994; Panneli et al., 2006). Consequently, several new cultivars have been released such as Barnea (Lavee et al., 1986) Fs-17 (Fontanazza et al., 1998) Maalot (Lavee et al., 1999) "Arno, Tevere and Basento" (Bellini et al., 2000) and Askal (Lavee et al., 2003).

Sampaio and Pinheiro, (2012) stated that the specific topics covered include: genetic diversity and genetic improvement; vegetative propagation; yield and quality of olive cultivars and disease management and cultivar resistance; and olive oil production and marketing.

Comparative field trials of advanced selections from breeding programs are currently carried out in several olive producing countries (Bellini, et al., 2000; Sonnoli et al., 2003; Lavee et al., 2004 and Alfei et al., 2008). A morphological scheme of primary descriptors which proved to be suitable for discriminating cultivars has been used to determine 262 cultivated olive varieties (Rallo, 1995). The secondary characterization of many cultivars is already underway as regards some criteria such as growth, productivity and fruit parameter (Del Rio and Caballero, 1994) and resistance to abiotic factors such as calcareous soils, drought and salinity (Corderio, 1997 and Cresti et al., 1997).

The main target of this breeding program was to select new olive cultivars with some preferable traits such as early bearing, high productivity and high oil 
content, resistance to pest and diseases, vigor suitability for mechanical harvesting and high quality of olive oil.

\section{Material and Methods}

An olive breeding program has been established in 1996 at Giza, Egypt using Koronaki; Manzanello; Picual and Arbquine olive cvs., (foreign cvs.) as mother plants for Hamed olive cv. (local cv.) as a pollinizer.

The resulting progenies were planted during 2000 season in the orchard of the Horticulture Research Institute at Giza, Egypt and evaluated during the 2011, 2012 \& 2013 growing seasons.

The evaluated progenies in this study were derived from crosses between cvs. Koronaki $\mathrm{x}$ Hamed, Manzanello x Hamed; Picual x Hamed and Arbquine $\mathrm{x}$ Hamed planting at the orchard of Horticulture Research Institute during 1996 and 1997 (Table, 1).

Table 1. Number of progenies derived from crosses combination.

\begin{tabular}{|c|c|}
\hline Selections & $9 \quad \mathrm{X} \quad 0^{1}$ \\
\hline 41 & Koronaki x Hamed \\
\hline 42 & Koronaki x Hamed \\
\hline 44 & Koronaki x Hamed \\
\hline 45 & Koronaki x Hamed \\
\hline 46 & Koronaki x Hamed \\
\hline 47 & Koronaki x Hamed \\
\hline 57 & Manzanello x Hamed \\
\hline 59 & Manzanello x Hamed \\
\hline 60 & Manzanello x Hamed \\
\hline 61 & Manzanello x Hamed \\
\hline 71 & Picual x Hamed \\
\hline 72 & Picual x Hamed \\
\hline 73 & Picual x Hamed \\
\hline 89 & Arbquine $\mathrm{x}$ Hamed \\
\hline 91 & Arbquine $\mathrm{x}$ Hamed \\
\hline 94 & Arbquine $\mathrm{x}$ Hamed \\
\hline 99 & Arbquine $x$ Hamed \\
\hline 100 & Arbquine x Hamed \\
\hline
\end{tabular}

The seedlings were planted on Sept., $25^{\text {th }} 2000$ at the same orchard with planting distance $4 \times 4 \mathrm{~m}$ apart where seedlings have a very long juvenile phase (15-20 years) under natural conditions begin to bearing fruit only. In order to shorten the length of the juvenility period, the plants must attain sufficient height and should be grown in the erect position. They should be maintained in a continuous growing phase and pruning should be avoided as far as possible with the exception of the lowest branches. Fertile substrates should be used with abundant fertilization when the seedlings reach the transition phase (i.e. from the juvenile to adult phase), which is characterized by the disappearance of the wild traits and the appearance of traits corresponding to the mature phase and the plants become potentially fertile. Standard cultural practices were followed including irrigation, fertilization and pest control.
The following characters were addressed by using the methodology for primary and secondary characterizations of olive cultivars proposed by the International Olive Council (Barranco et al., 2000). Twenty shoots were labeled on each seedling in different directions to study shoot growth, flowering and fruiting. Thirty fruits from previously tagged flowers were randomly collected at the time of ripening index to avoid the influence of the ripening stage on fruit traits and rooting ability.

Evaluation of the studied progenies was performed through determining the following traits:-

1- Tree growth parameters. Shoot length $(\mathrm{cm})$, shoot thickness $(\mathrm{cm})$, number of nodes/shoot, internodes length $(\mathrm{cm})$.

a- Leaves: (Average number of leaves/shoot, the leaf surface area $\left(\mathrm{cm}^{2}\right)$ and leaf shape).

b- Leaf Shape: This determined by the ratio between the length (L) and the width (W). Elliptic: L/W < 4, Elliptic-lanceolate: L/W 4-6, lanceolate: L/W > 6.

\section{2- Blooming:}

Flowering time, (start, end and duration) the length of inflorescence, number of total flowers/inflorescence, number of perfect flower/ inflorescence, number of staminate flowers/ inflorescence and sex ratio.

\section{3- Fruiting:}

a) Fruit set/m

b) Yield $(\mathrm{kg}) /$ tree, fruit shape, fruit weight, stone weight.

4- Fruit quality: flesh weight and flesh/stone. Moisture and oil content (oil content in fresh weight and oil percent in dry weight). Fruit shape: This determined by the ratio between the length $(\mathrm{L})$ and the width (W). Spherical: L/W < 1.25, Ovoid: L/W 1.251.45 , Elongated: $\mathrm{L} / \mathrm{W}>1.45$. Fruit weight: very low $<2$ g, low 2-4 medium 4-6 g, high 6-8 g, very high $>8 \mathrm{~g}$. Flesh/stone: low $<5$, medium 5-7.5, high 7.5-10, very high $>10$.

5- Rooting ability: Leafy stem cuttings to be taken from trees on "off" years (in the middle of spring or late summer) and treated with $3000 \mathrm{ppm}$ indolebutyric acid (IBA).

The following categories have been established according to the international olive council (Barranco et al., 2000).

Rooting (\%): nil 0, very low 1- 20, low 20-40 medium 40-60 high 60-80, very high 80-100.

\section{Results and Discussion}

\section{1- Tree growth parameters:}

a- Shoot length (cm).

It is obvious from Fig., 1 that progenies No. 100, 99 and 94 derived from cvs. (Arbiquine x Hamed) produced the longest shoots than parental cultivars. 
While progenies No 46 and 47 derived from cv. (Koronaki x Hamed) gave the shortest shoots than the parental cultivars.

\section{b- Shoot thickness (cm).}

Fig., 2 illustrates that the shoots of progenies No. 59 and 60 (Manzanillo x Hamed) were the thicker as well as, progeny No. 100 (Arbiquine $\mathrm{x}$ Hamed), more than the those of cvs. Koronaki, Hamed, Manzanillo, Picual and Arbiquine. On the other side, shoot of progeny No. 47 (Koronaki x Hamed) and No. 72 (Picual $x$ Hamed) had the thinnest value. The standard error is ranging from 0.03 to 0.30 .

\section{c- Number of nodes/shoot.}

It is quite evident from data in Fig., 3 that the progenies No. 98, 99, and 94 derived from (Arbiquine $\mathrm{x}$ Hamed), had the highest number of nodes and short than cv. Hamed compared to all other studied progenies. On the other side, progenies No. 46 and 47 derived from (Koronaki x Hamed) gave the lowest value of number of nodes/shoot.

\section{d- Internodes length (cm.).}

It is clear from Fig., 4 that progenies No. $100 \&$ 99 (Arbiquine x Hamed) and No. 59 (Manzanillo x Hamed) gave the longest internodes than cvs. Koronaki, Hamed, Manzanillo, Picual and Arbiquine cvs., while the shortest internodes were progenies No. 60 \& 61 (Manzanillo x Hamed) and 46 \& 47 (Koronaki x Hamed). The standard error is ranging from 0.02 to 0.12 .

\section{e- Number of leaves/shoot.}

Fig., 5 shows that progenies No. 98, 99 and 94 (Arbiquine $\mathrm{x}$ Hamed) scored the highest values in this respect than the cvs. Parents, while the lowest value was obtained by progeny No. 46 (Koronaki $x$ Hamed).

\section{f- Leaf surface area.}

Leaf surface area varied among the tested progenies as shown in Fig., 6. Progeny No. 72 derived from (Picual $x$ Hamed) recorded the highest values in this concern than cv. Picual. Whereas the lowest value was produced by progeny No. 89 (Arbiquine $\mathrm{x}$ Hamed). The rest progenies gave an intermediate values.

\section{g- Leaf shape.}

Fig., 7 shows that the progeny No 73 derived from (Picual x Hamed) and No. 99 derived from (Arbiquine $\mathrm{x}$ Hamed), as well as, progeny No 46 derived from (Koronaki $\mathrm{x}$ Hamed) took Elliptic lance-date leaf shape like, Koronaki, Hamed, Manzanillo, Picual and Arbiquine cvs.

Differences in growth characteristics among olive selections are in close conformity with the findings previously reported by many researchers (Bellini et al., 1990 and 2000, Rallo, 1995, Trigui
1996, Damijela, et al 2008, Pritsa et al., 2003, Bartolini et al., 2006, and Bellini et al., 2008).

\section{2- Blooming. \\ a- Flowering time (start, end and duration).}

Table 2 demonstrates that progenies derived from cvs. (Koronaki x Hamed) began flowering during $12 / 3$ to $23 / 3$, meanwhile the progenies derived from cvs. (Manzanillo x Hamed) began flowering during $11 / 3$ to $18 / 3$; (Picual $x$ Hamed) began flowering during $22 / 3$ to $25 / 3$ the fourth group of progenies, flowering began during 18-21/3.

\section{b- Number of total flowers/inflorescence.}

It is clear from Fig. (8) that the number of flowers/ inflorescence was 27.55. Progenies No. 100 (Arbiquine x Hamed), No 61 (Manzanillo x Hamed) and No. 47 (Kronaki x Hamed) scored the highest number of flowers/ inflorescence. On the other hand, the progeny No. 72 (Picual x Hamed) had the lowest values and the rest progenies gave intermediate values in this.

\section{c- Number of perfect flowers/ inflorescence.}

Fig., 9 indicates marked variations among tested progenies. The highest values of perfect flowers were in progenies No. 61 (Manzanillo $\mathrm{x}$ Hamed) and No 100 and 99 (Arbiquine x Hamed) than cvs. Koronaki, Hamed, Manzanillo, Picual and Arbiquine.

\section{d- Number of male flowers/ inflorescence.}

Fig., 10 illustrates that progenies No. 72 (Picual $x$ Hamed) and No 61 (Manzanillo x Hamed) gave the lowest values than cvs. Koronaki, Hamed, Manzanillo, Picual. On the other hand, progenies No. 98 (Arbiquine x Hamed) and No. 57 (Manzanillo x Hamed) gave the highest values and the rest progenies gave intermediate numbers.

\section{e- Inflorescence length.}

Fig., 11 demonstrates that progenies No. 60 (Manzanillo x Hamed); and No. 45 (Koronaki x Hamed) and No. 100 (Arbiquine $x$ Hamed) gave the highest value than cvs. Manzanillo, while progeny No. 57 (Manzanillo x Hamed) scored the lowest value, in this respect.

Differences in growth characteristics among olive progenies are in close conformity with the findings previously reported by Bellini et al., (2000), Ferri et al., (2006), Bellini et al., (2008) and Hechmi et al., (2012).

\section{f- Sex ratio:}

Data in Fig. (12) shows that progenies No. 61 (Manzanillo x Hamed), No 99 (Arbiquine x Hamed) and No. 46 (Koronaki x Hamed) gave the highest value than the cvs. Manzanillo; Hamed; Koronaki, whereas progenies No. 59 \& 98 (Manzanillo x Hamed) and (Arbiquine x Hamed), scored the lowest 
values respectively. The rest progenies gave intermediate values in this concern.

\section{3- Tree fruiting: \\ a- Fruit set $/ \mathbf{m}$}

Fig., 13 shows that the highest fruit set values were achieved by progenies No. 72 and 73 (Picual x Hamed) and No. 61 (Manzanillo x Hamed) than cvs. Koronaki; Manzanillo and Hamed. Conversely, the lowest values were produced by progeny No. 45 (Koronaki x Hamed).

\section{b- Yield (kg)/tree.}

Fig., 14 illustrates that progenies No. 72 and 71 (Picual $x$ Hamed) were the most promising progenies in producing the highest yield, that scored between 32.13 to $32.00 \mathrm{~kg} /$ tree than the parents cvs. Picual and Hamed, followed by progenies No. 45, 41 and 47 (Koronaki x Hamed). Also rather than the parents cvs. Koronaki and Hamed. The least total yield was produced by progenies No. 73 and 99 (Picual $x$ Hamed) and (Arbiquine $x$ Hamed), respectively.

Progenies No. 72 and 71 (Picual x Hamed) scored constant yield during the three years. The standard error is ranging for those progenies are ranging from 2.59 to 2.46; also the progenies No. 45; 41 and 47 (Koronaki $x$ Hamed) gave constant productivity the standard error is $2.46 ; 1.59$ and 0.88 .

Similar results in the Olive Germoplasm Bank of Cordoba showed mean accumulated fruit yield in the first three years of bearing from 2 to $52 \mathrm{~kg}$ per tree among cultivars (Leon $\boldsymbol{e t}$ al., 2006).

\section{4- Fruit quality. \\ a- Fruit shape.}

Data in Fig, 15 show that progenies No 89 resulted from (Arbiquine $\mathrm{x}$ Hamed) take elongated fruit shape like cv. Arbiquine, but progenies No 41, 42 and 44 resulted also from (Koronaki x Hamed) took the ovoid fruit shape like cv. Koronaki and progenies No 71 and 72 resulted from (Picual $x$ Hamed) took avoid fruit shape like cv. Picual.

\section{b- Fruit weight, seed weight, flesh weight and flesh/seed.}

Figs., 16, 17, 18 and 19 illustrate showed that progenies derived from (Manzanillo x Hamed) produced the highest fruit weight. It was ranging between 2.03 to $5.91 \mathrm{gm}$, more than the fruits for cvs. Manzanillo and Hamed. Followed by (Arbiquine $\mathrm{x}$ Hamed) it was ranging between 2.63 to $5.75 \mathrm{gm}$. while progenies derived from (Picual $\mathrm{x}$ Hamed) gave the lightest fruit weight. It was ranging from 1.80 to $2.27 \mathrm{gm}$. On the other hand, the progenies derived from (Koronaki x Hamed) gave intermediate values which ranged between 2.31 to $2.83 \mathrm{gm}$.

Concerning seed weight and flesh weight they took an analogous trend to the fruit weight. As for determination of flesh to seed ratio, the resulting progenies showed a large variation in this parameter, ranging from 2.67 to 7.09 , the highest value of $\mathrm{F} / \mathrm{S}$ ratio was noticed with progeny No. 99 (Arbiquine $\mathrm{x}$ Hamed) more than cvs. Parents, followed by progenies No. 89 and 98 (Arbiquine x Hamed) also more than cvs. parents. The F/S ratio is extremely important because it is an indication for oil content.

\section{c- Moisture content.}

Moisture content is a major factor for olives as it generally contributes to more that $50 \%$ of the fruit weight. Fig, 20 shows that the mean moisture content was generally high, around $67.58 \%$. The progenies derived from (Koronaki x Hamed) showed that the moisture was ranging from 64.07 to $66.70 \%$, as well as the progenies derived from (Manzanillo x Hamed) showed that the moisture content was ranging between 65.67 to 67.46 , also, the progenies derived from (Picual $x$ Hamed) showed that the moisture content was ranging between 63.56 to 66.80 and the last group progenies derived from (Arbiquine $\mathrm{x}$ Hamed) showed that the moisture content was ranging between 64.72 to 66.53 .

Moisture content of the fruit is important to oil quality for a number of reasons, if the fruit moisture level drops to a point where desiccation occurs, cell break down can follow leading to increase of free fatty acids and therefore lower oil quality (Ayton, et al., 2001).

\section{d- Oil content in fresh weight.}

Olive fruit yield and oil content are the major contributors of profitability olive growers. The for average oil $\%$ extracted was determined and is illustrated in Fig, 21 oil content is expressed as a percentage of the fresh weight of olives. Progenies derived from (Koronaki $x$ Hamed) showed that the oil content was which ranged from $17.99 \%$, to 18.58 $\%$. On the other side, oil progenies derived from (Manzanillo x Hamed) showed that the oil content was ranged from $17.43 \%$ to $17.92 \%$, followed by progenies derived from (Picual $\mathrm{x}$ Hamed) showed that the oil content was ranging from $18.03 \%$ to $19.15 \%$ and the last group progenies derived from (Arbiquine $\mathrm{x}$ Hamed) showed that oil content was ranged between $18.06 \%$ to $18.35 \%$.

\section{e- Oil percent in dry weight.}

As fresh weight is influenced by several factors such as a tree crop and climatic conditions, oil content on a fresh weight cannot be taken into consideration in a comparative quality. This is a reason for using oil content per olive as a fixed criterion, disregarding weight. 


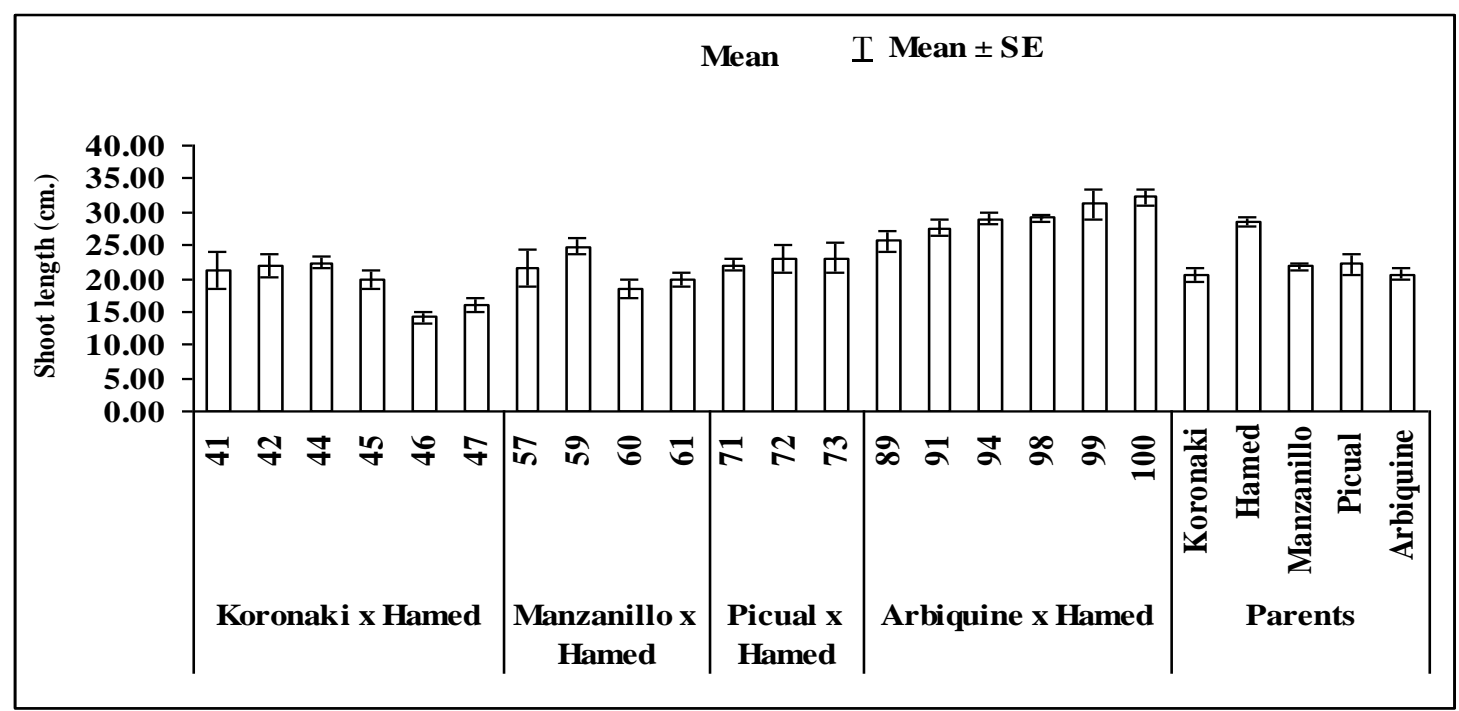

Fig., 1. Mean and standard error during three seasons for shoot length $(\mathrm{cm}$.$) of the olive progenies.$

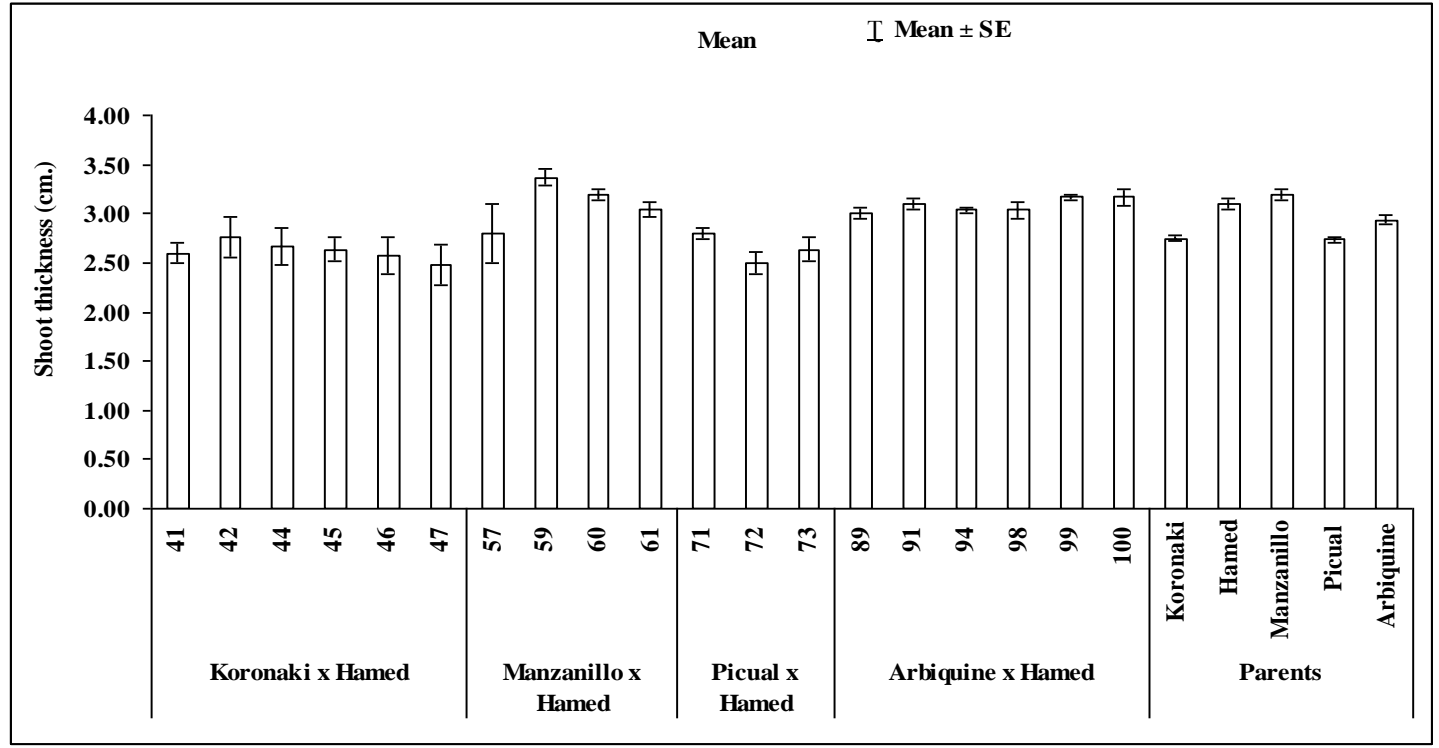

Fig., 2. Mean and standard error during three seasons for shoot thickness $(\mathrm{cm}$.) of the olive progenies.

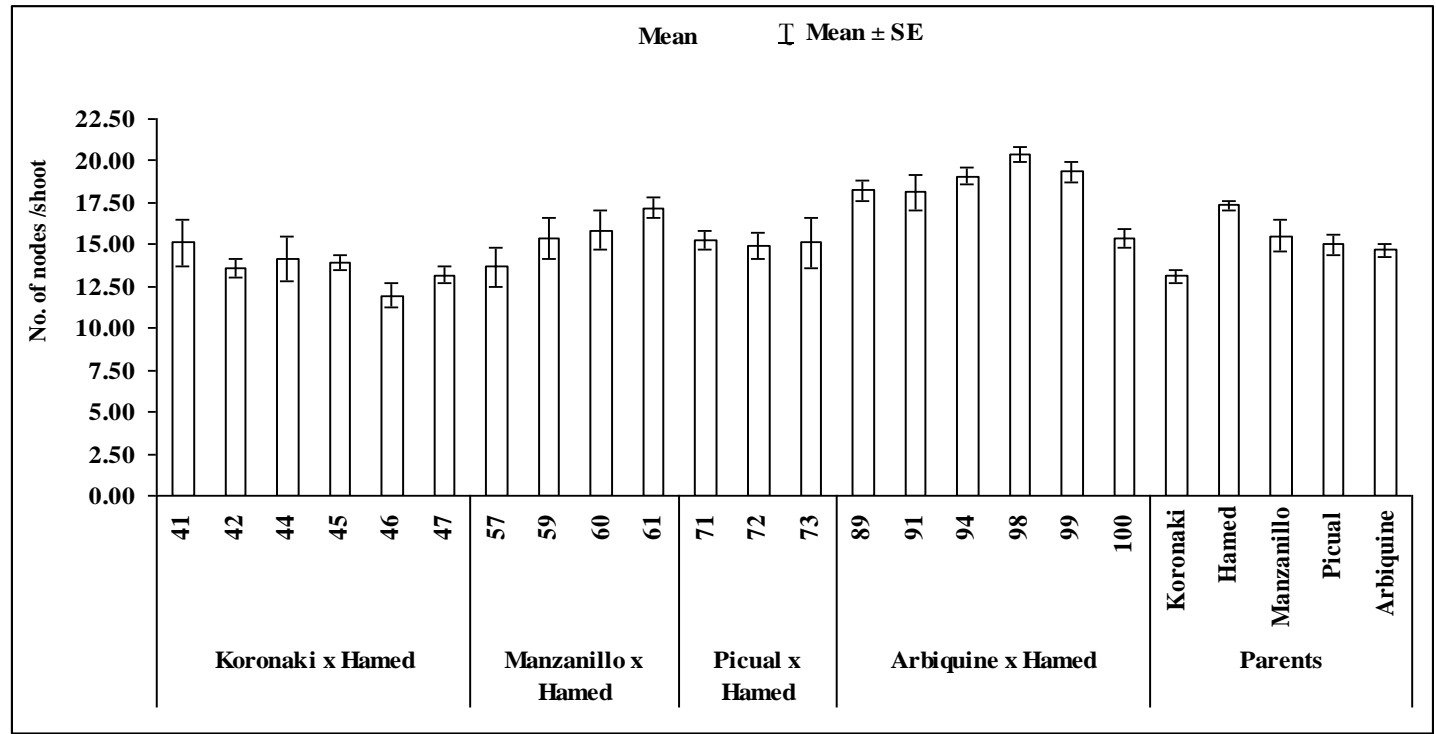

Fig., 3. Mean and standard error during three seasons for no. of nodes /shoot of the olive progenies. 
Data presented in Fig, 22 clearly indicate that oil content in dry weight was ranging from 51.73 to 54.08. \% in progenies derived from (Koronaki $\mathrm{x}$ Hamed), but less than cv. Koronaki. On the other side, progenies derived from (Manzanillo x Hamed) showed that the oil content scored from 51.65 to $55.08 \%$. Also, progenies derived from (Picual $\mathrm{x}$ Hamed) showed that the oil content was ranged from 52.55 to $54.39 \%$. The last group progenies derived from (Arbiquine $\mathrm{x}$ Hamed) showed that the oil content ranged between $51.91 \%$ to $53.98 \%$ and gave the highest oil percent in dry weight and more than cv. Arbiquine.
Differences in growth characteristics among olive selections are in close conformity with the findings previously reported by many researchers (Saad El-Din et al. 2009, Esmaeili, et al., 2012, Hechmi et al., 2012 and Medina et al., 2012).

\section{5- \% Rooting ability.}

Rooting ability of the semi hardwood cutting is reported in Fig, 23 it is varied from 17.40 to 22.73 . All the progenies were classified as with moderate rootability.

Table 2. Time of flowering (start, end and duration).

\begin{tabular}{cccc}
\hline Progeny No & Start of blooming & End of blooming & Blooming duration \\
\hline 41 & $19-3$ & $11-4$ & 23 \\
42 & $23-3$ & $14-4$ & 22 \\
44 & $20-3$ & $11-4$ & 21 \\
45 & $15-3$ & $5-4$. & 24 \\
46 & $17-3$. & $10-4$ & 23 \\
47 & $12-3$ & $4-4$. & 23 \\
57 & $11-3$ & $2-4$. & 24 \\
59 & $14-3$. & $7-4$. & 20 \\
60 & $16-3$. & $5-4$. & 20 \\
61 & $18-3$ & $7-4$. & 22 \\
71 & $23-3$. & $14-4$. & 22 \\
72 & $25-3$. & $16-4$. & 25 \\
73 & $22-3$ & $16-4$. & 21 \\
89 & $20-3$ & $10-4$. & 23 \\
91 & $19-3$ & $11-4$. & 20 \\
94 & $21-3$ & $10-4$. & 22 \\
94 & $18-3$ & $9-4$. & 20 \\
99 & $23-3$. & $12-4$. & 21 \\
100 & $20-3$ & $10-4$ & 23 \\
Koronaki & $15-3$ & $7-4$ & 23 \\
Hamd & $22-3$ & $14-4$ & $\mathbf{2 2}$ \\
Picual & $30-3$ & $21-4$ & 21 \\
Arbquine & $20-3$ & $10-4$ & $1-4$ \\
Manzanello & $10-3$ & & 22
\end{tabular}




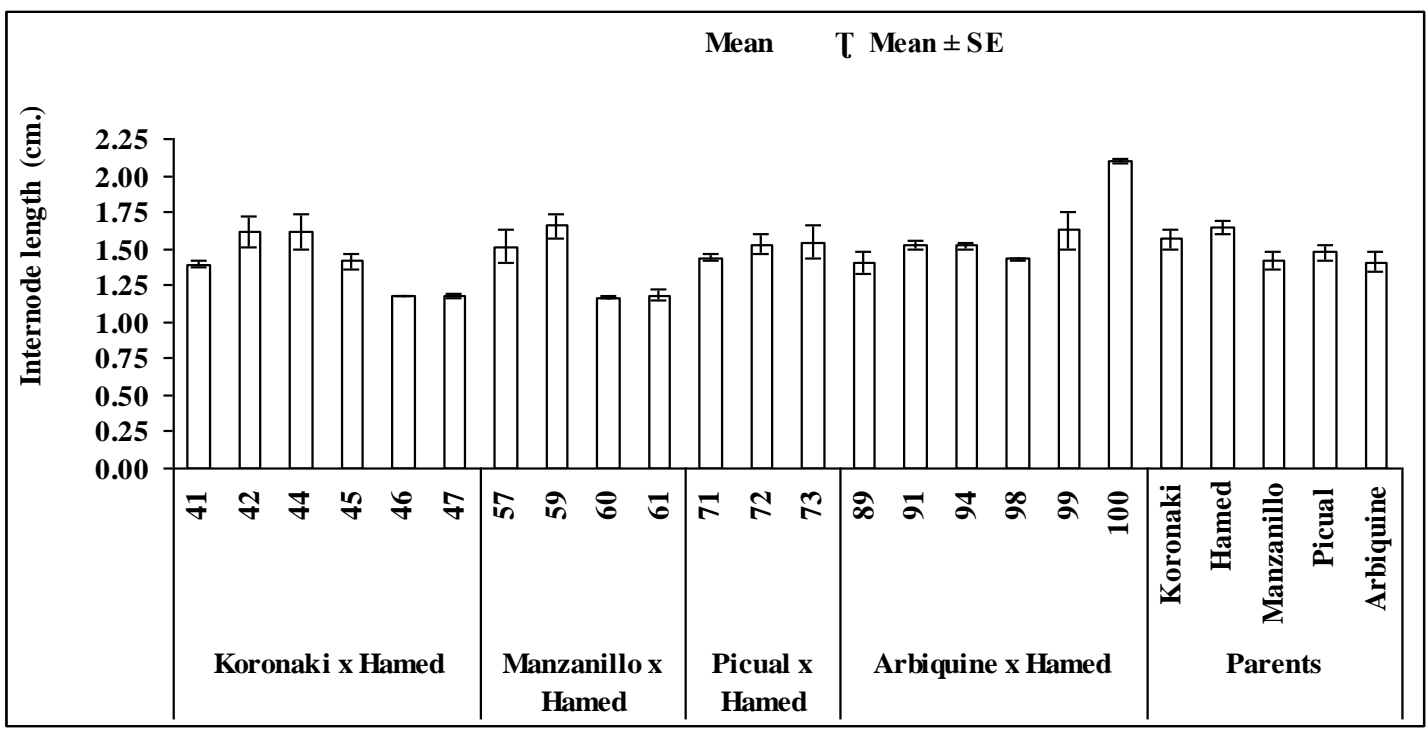

Fig., 4. Mean and standard error during three seasons for internodes length $(\mathrm{cm}$.) of the olive progenies.

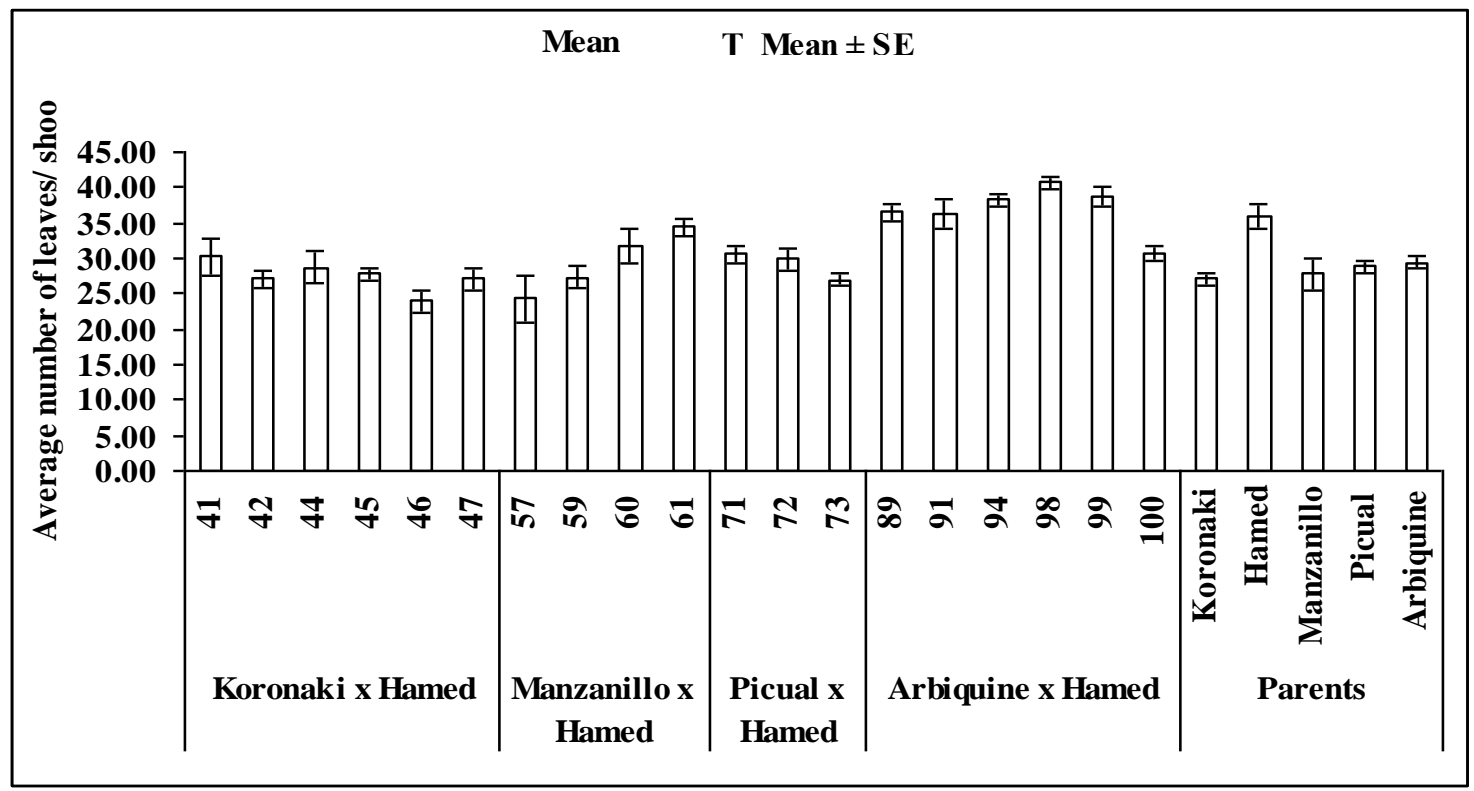

Fig., 5. Mean and standard error during three seasons for average number of leaves/ shoot of the olive progenies.

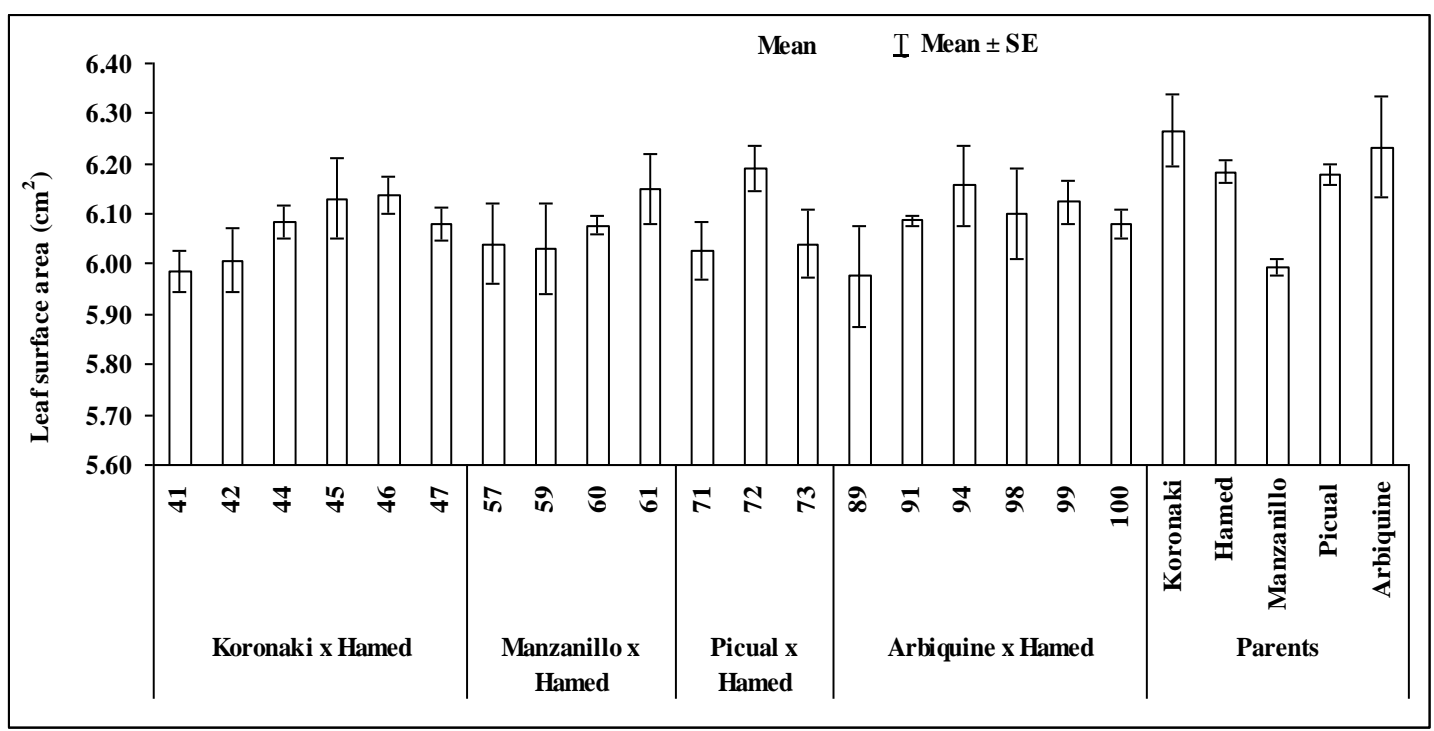

Fig., 6. Mean and standard error during three seasons for leaf surface area $\left(\mathrm{cm}^{2}\right)$ of the olive progenies. 




Fig., 7. Mean and standard error during three seasons for leaf shape of the olive progenies.

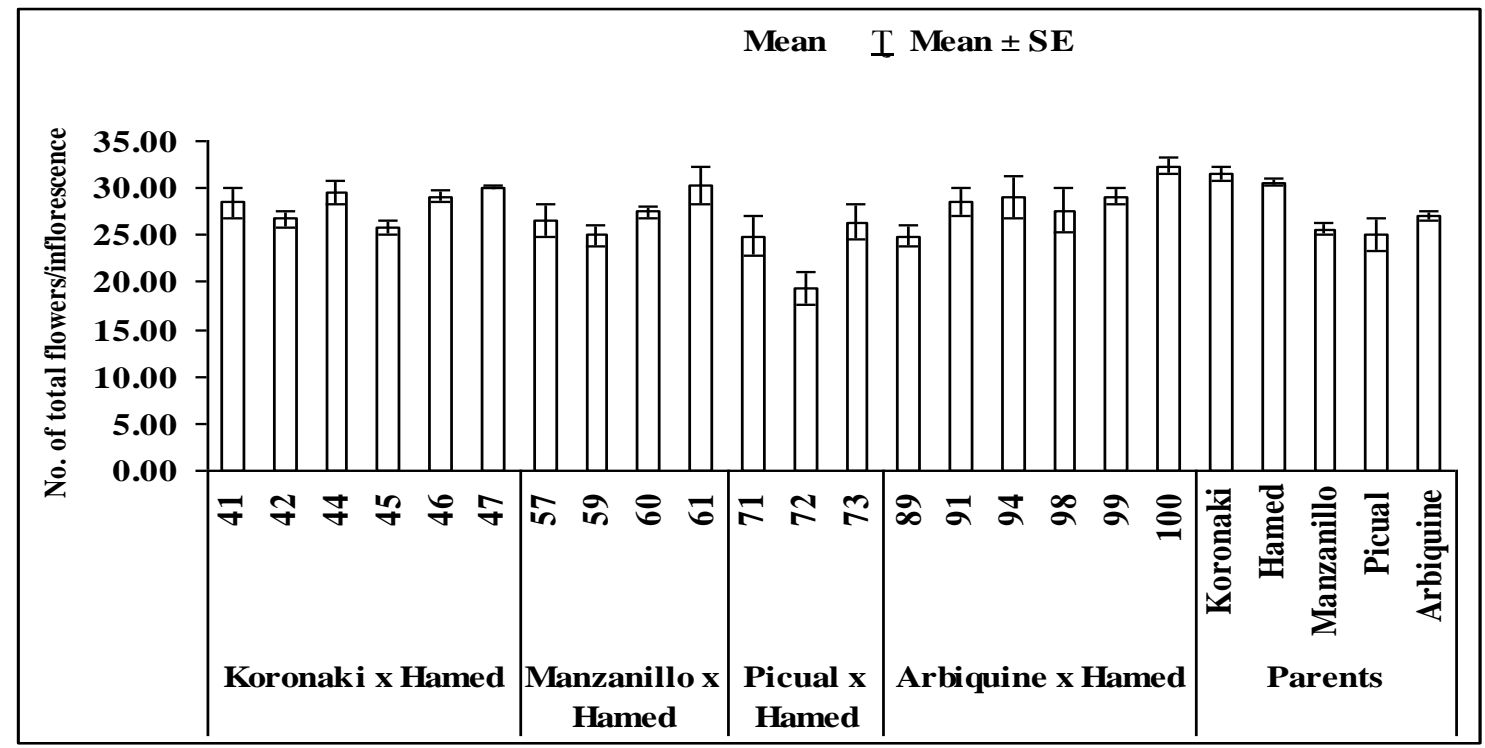

Fig., 8. Mean and standard error during three seasons for no. of total flowers/inflorescence of the olive progenies.



Fig., 9. Mean and standard error during three seasons for perfect flowers/ inflorescence of the olive progenies. 


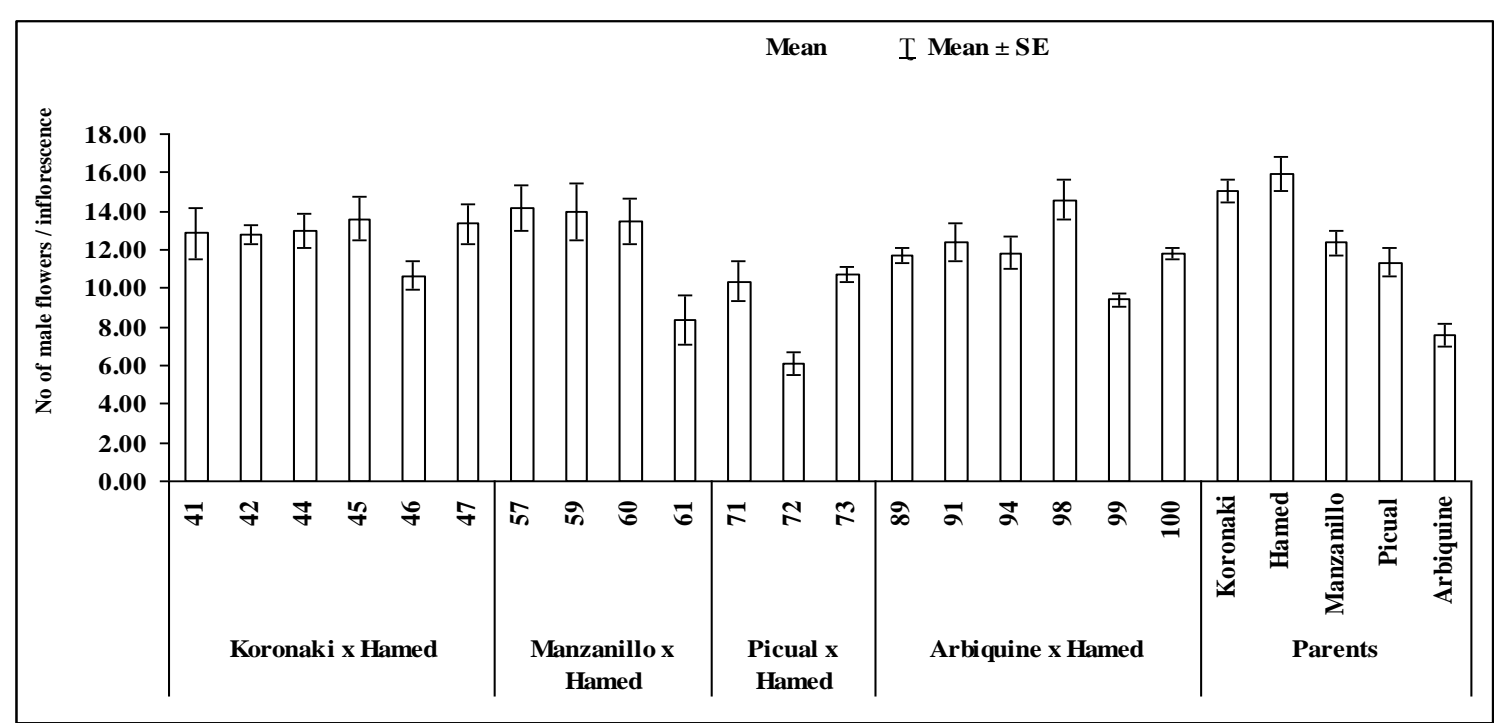

Fig, 10. Mean and standard error during three seasons for no of male flowers/inflorescence of the olive progenies.

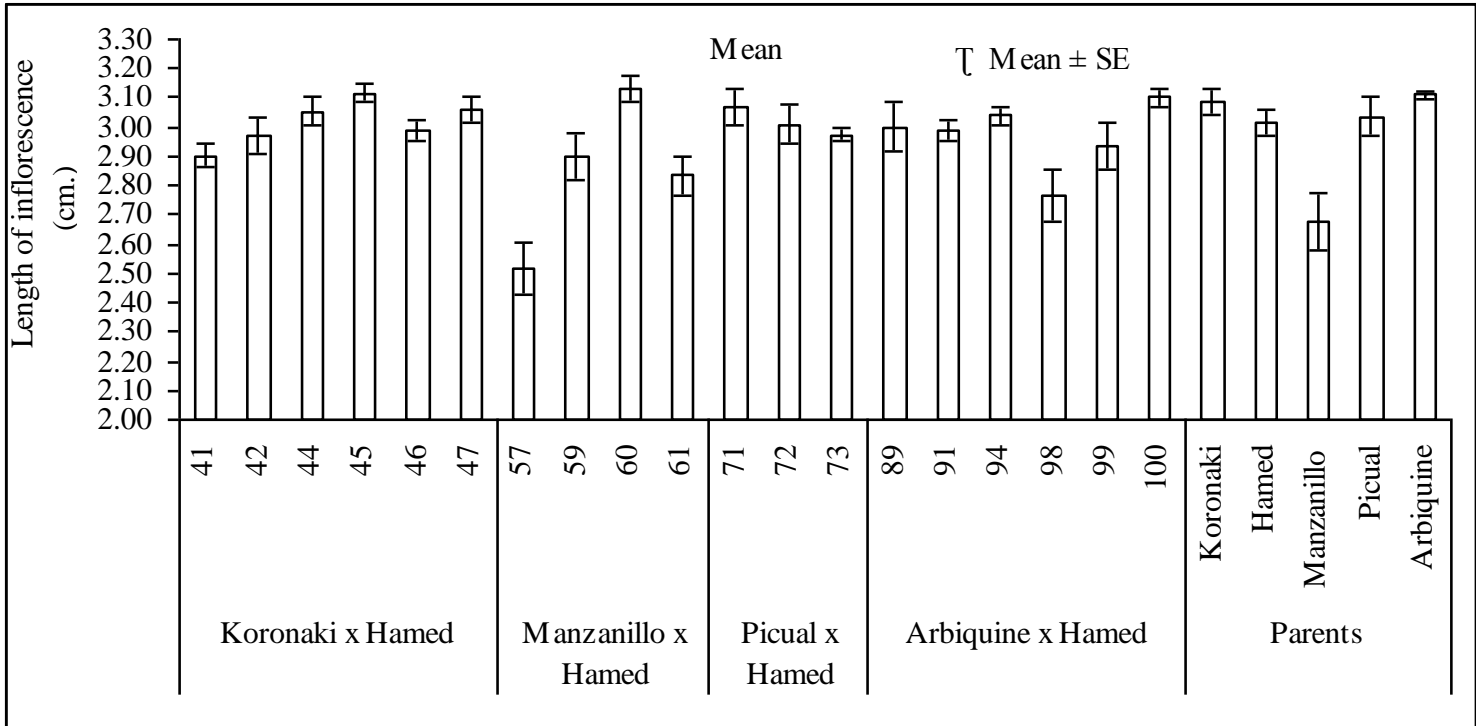

Fig, 11. Mean and standard error during three seasons for length of inflorescence $(\mathrm{cm}$.$) of the olive progenies.$

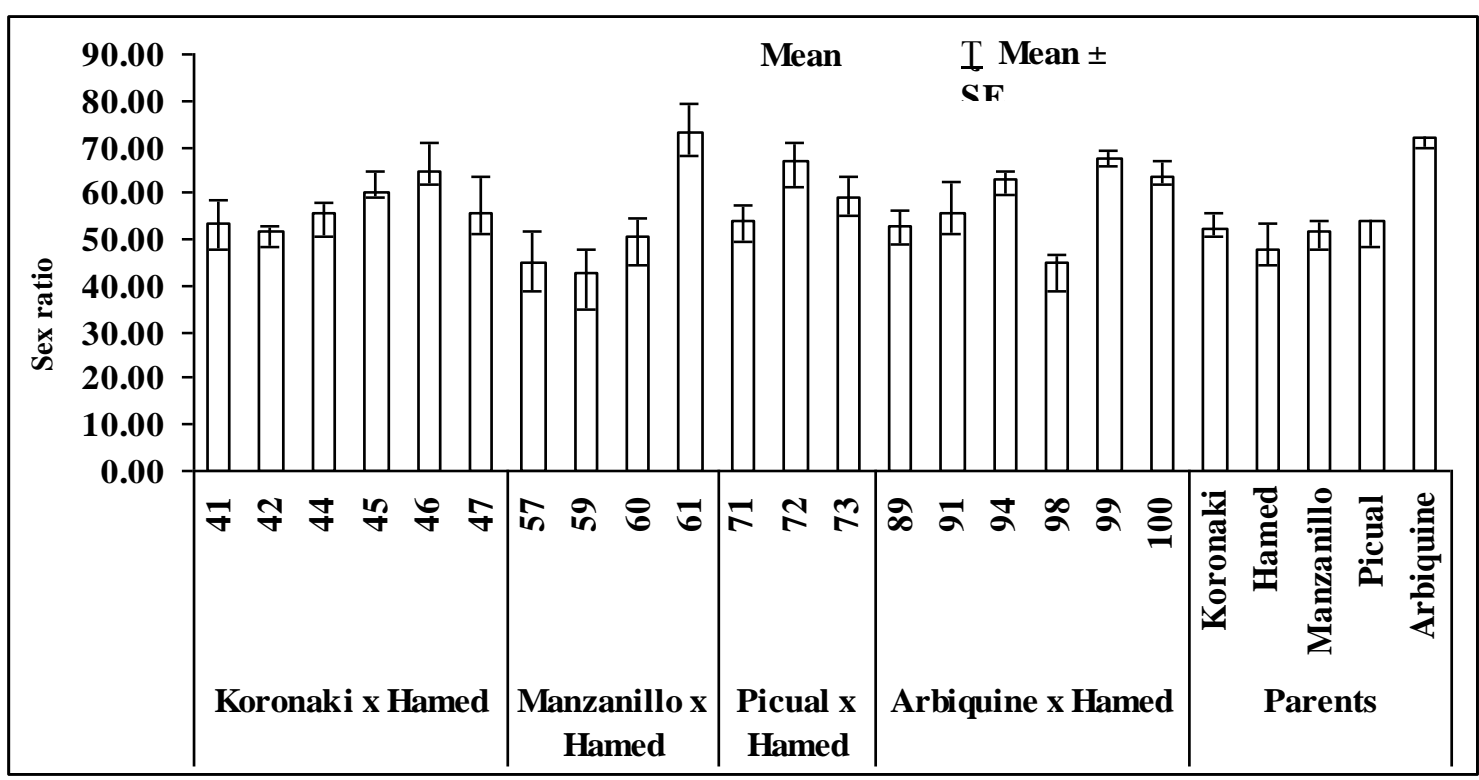

Fig, 12. Mean and standard error during three seasons for sex ratio of the olive progenies. 


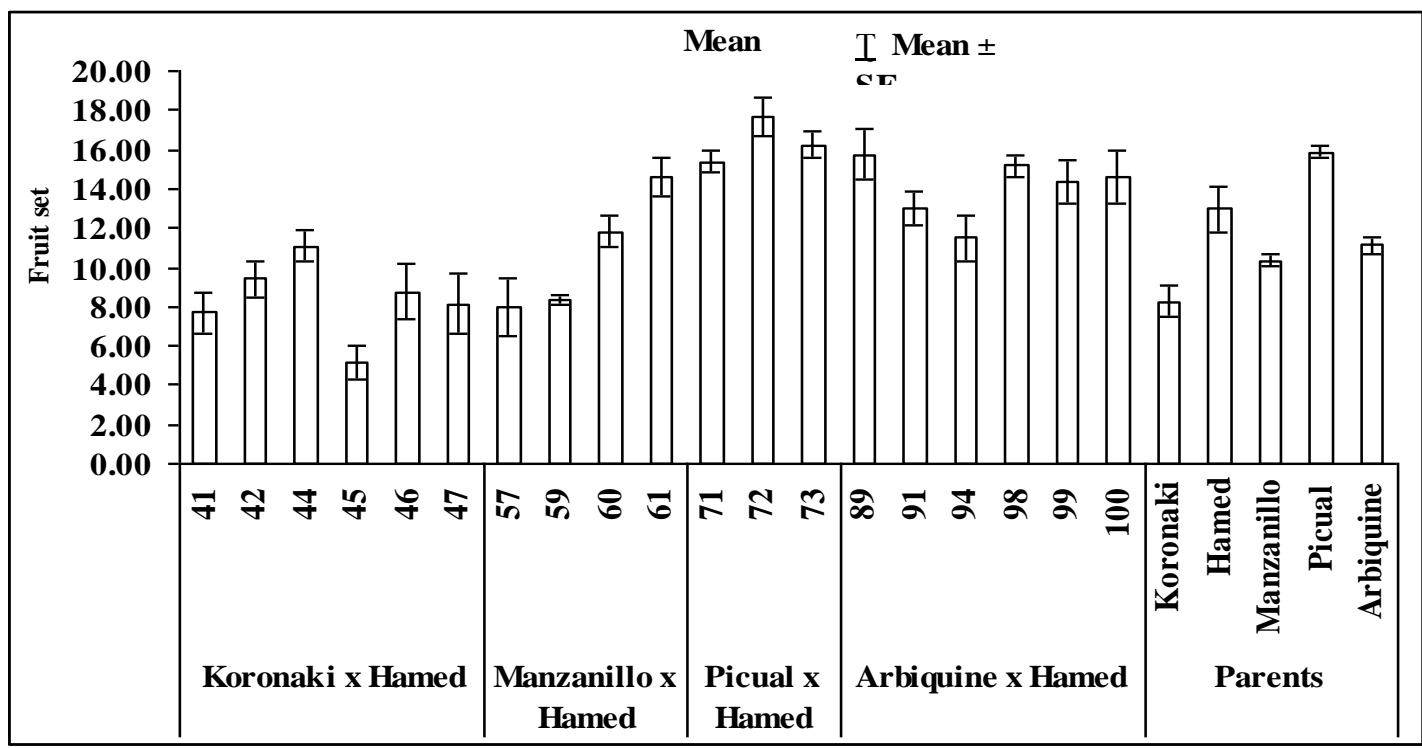

Fig, 13. Mean and standard error during three seasons for fruit set of the olive progenies.

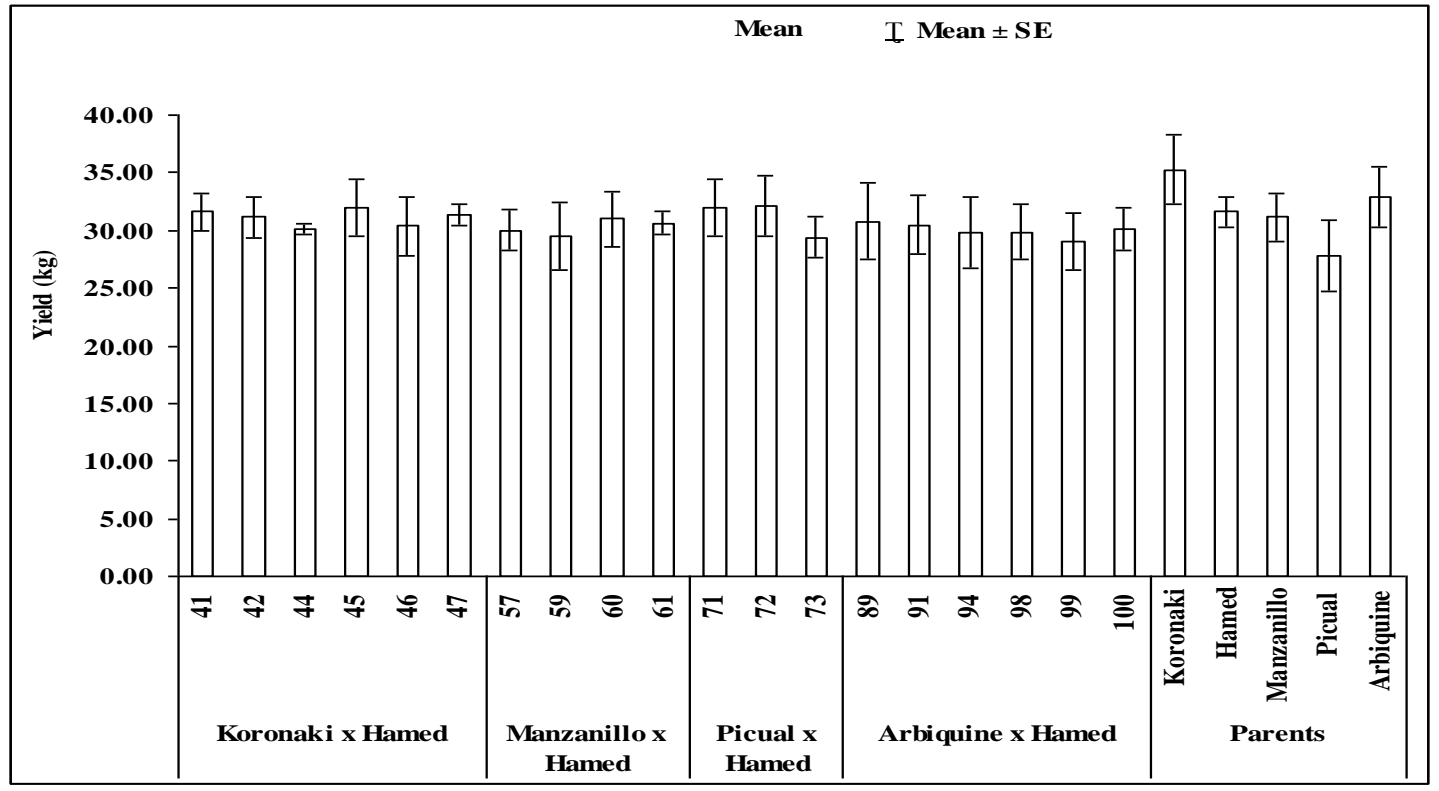

Fig, 14. Mean and standard error during three seasons for yield $(\mathrm{kg})$ of the olive progenies.

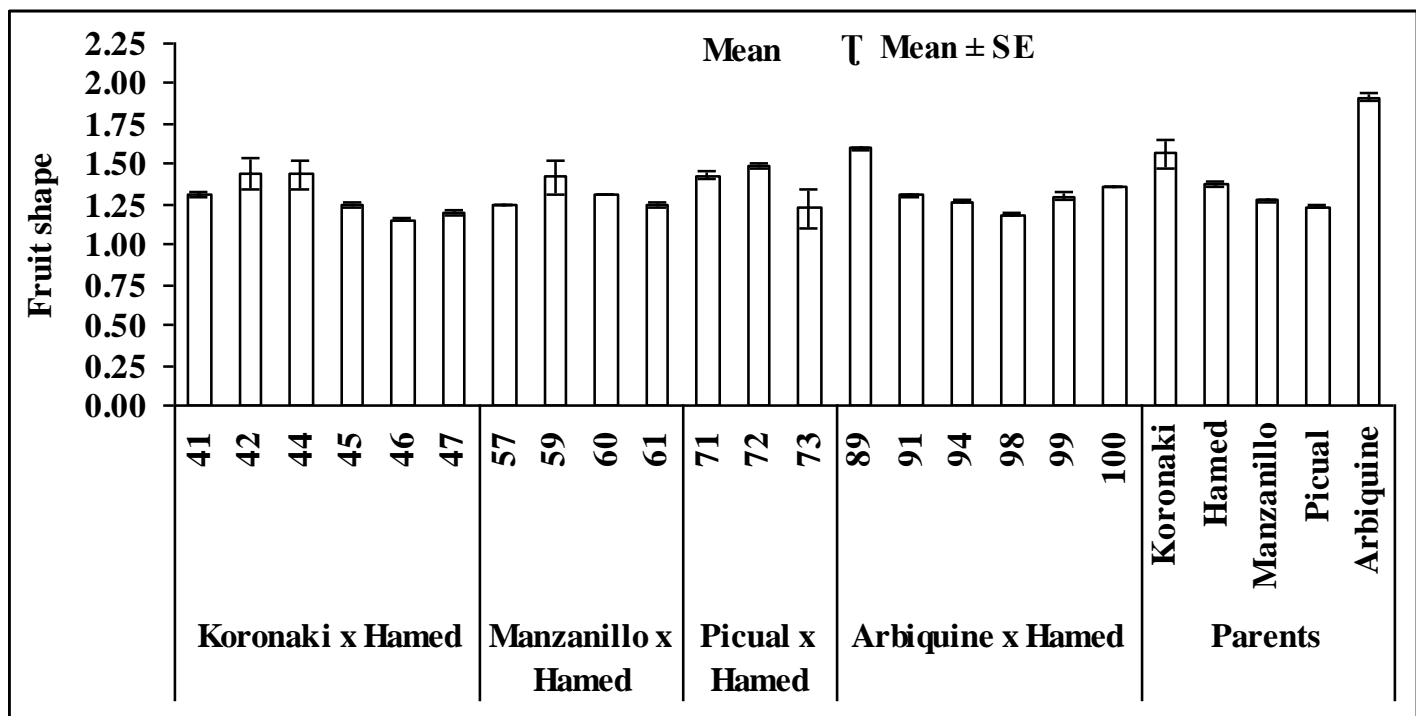

Fig, 15. Mean and standard error during three seasons for fruit shape of the olive progenies. 


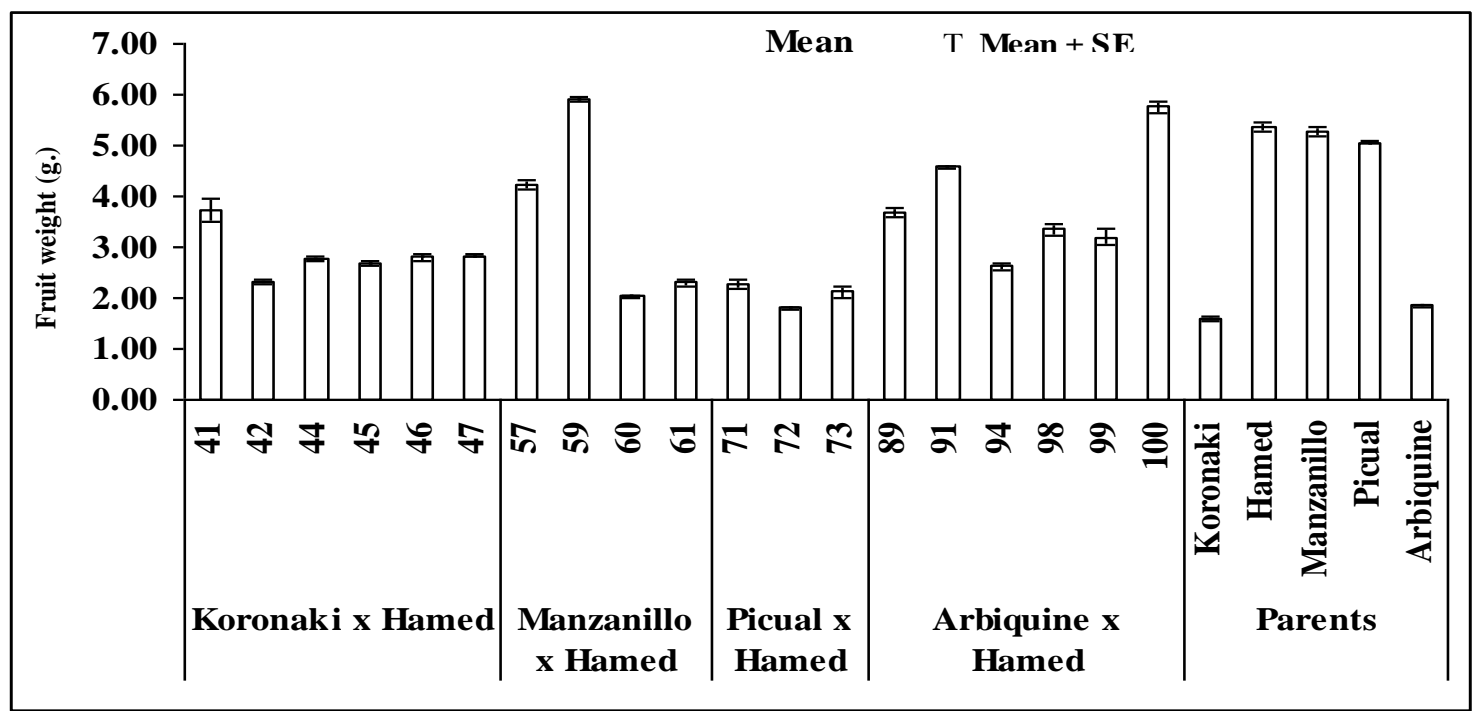

Fig, 16. Mean and standard error during three seasons for fruit weight (g.) of the olive progenies.

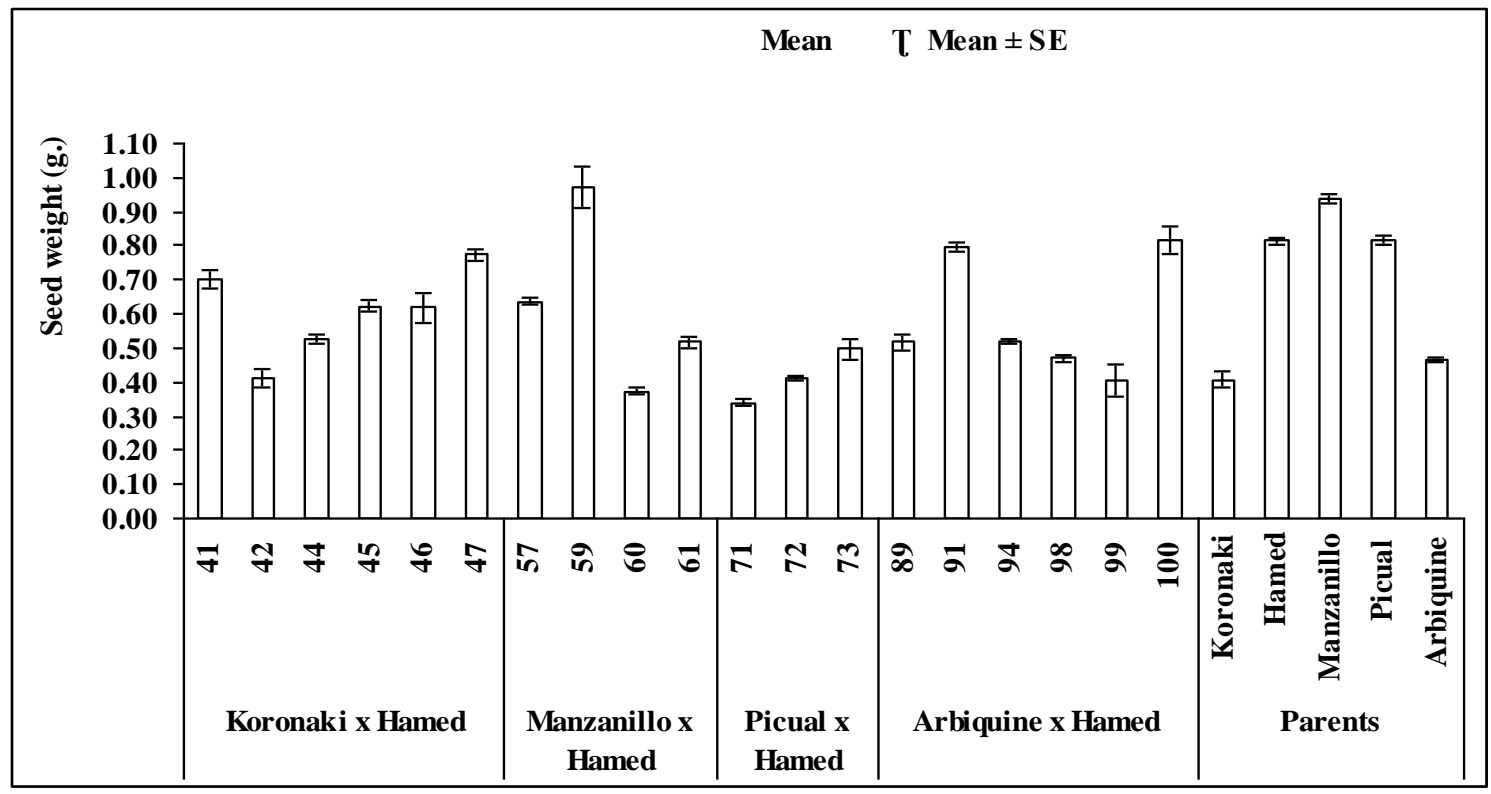

Fig, 17. Mean and standard error during three seasons for seed weight (g.) of the olive progenies.

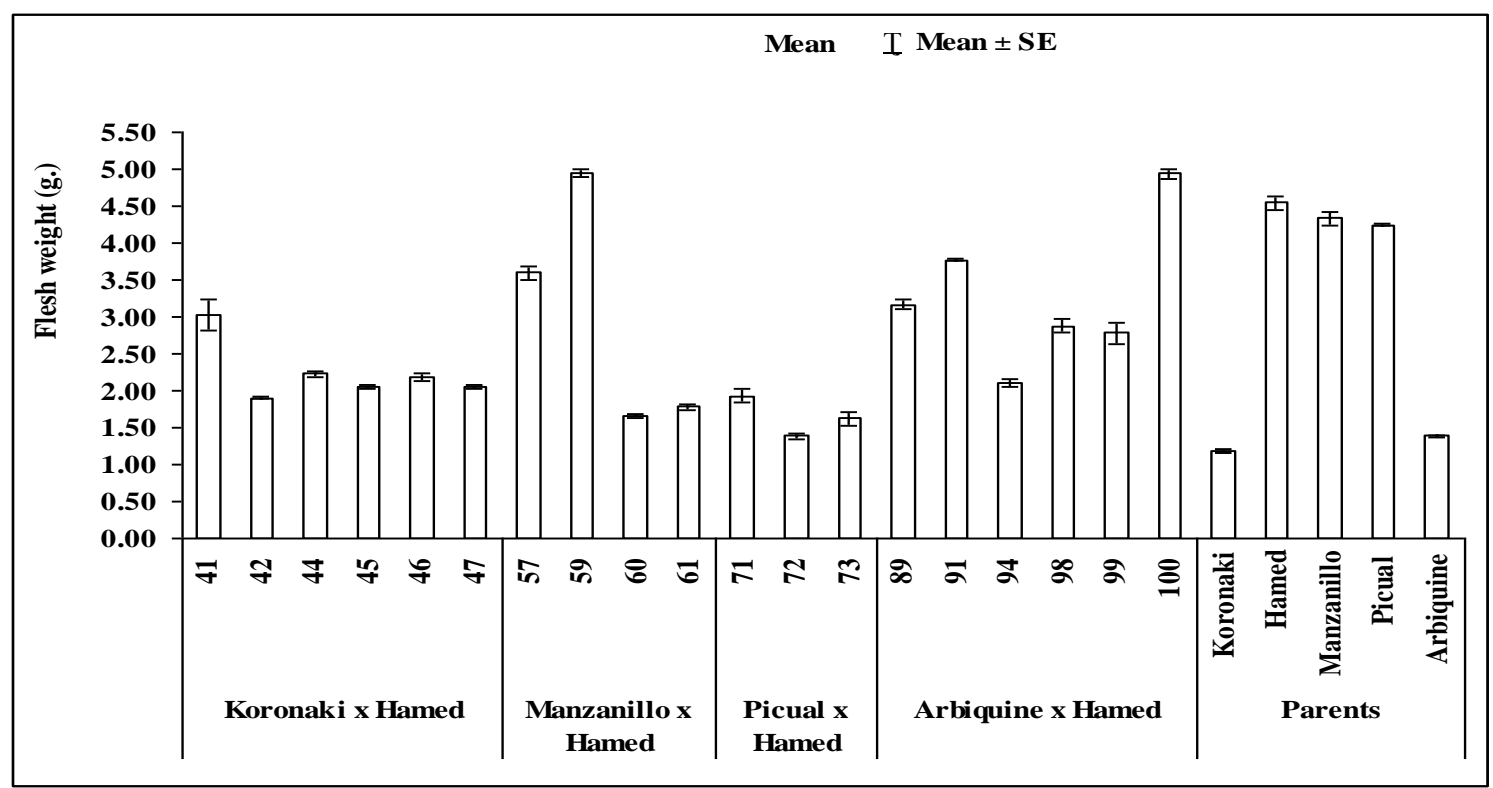

Fig, 18. Mean and standard error during three seasons for flesh weight (g.) of the olive progenies. 


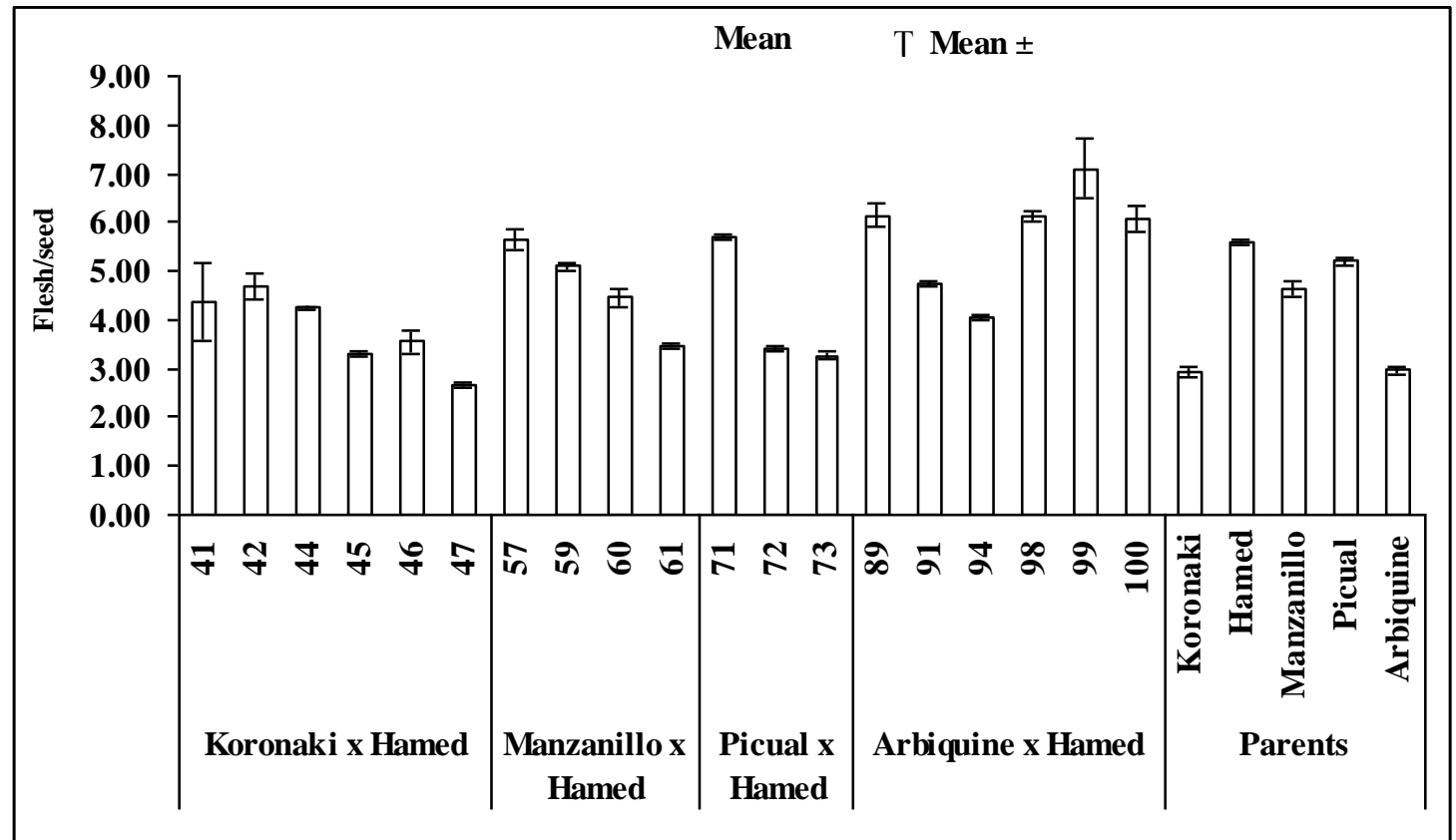

Fig, 19. Mean and standard error during three seasons for flesh/seed of the olive progenies.

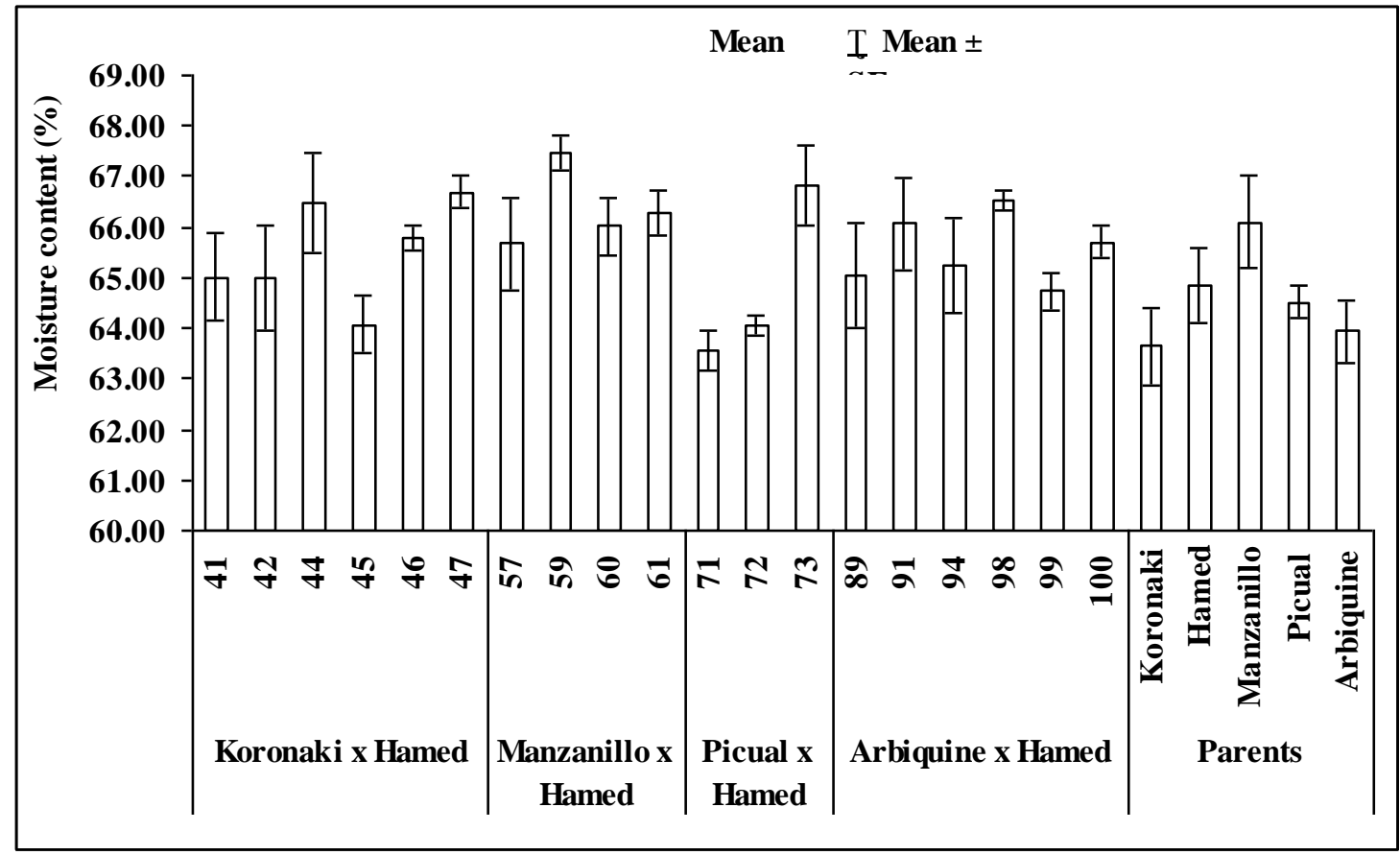

Fig, 20. Mean and standard error during three seasons for moisture content $(\%)$ of the olive progenies. 


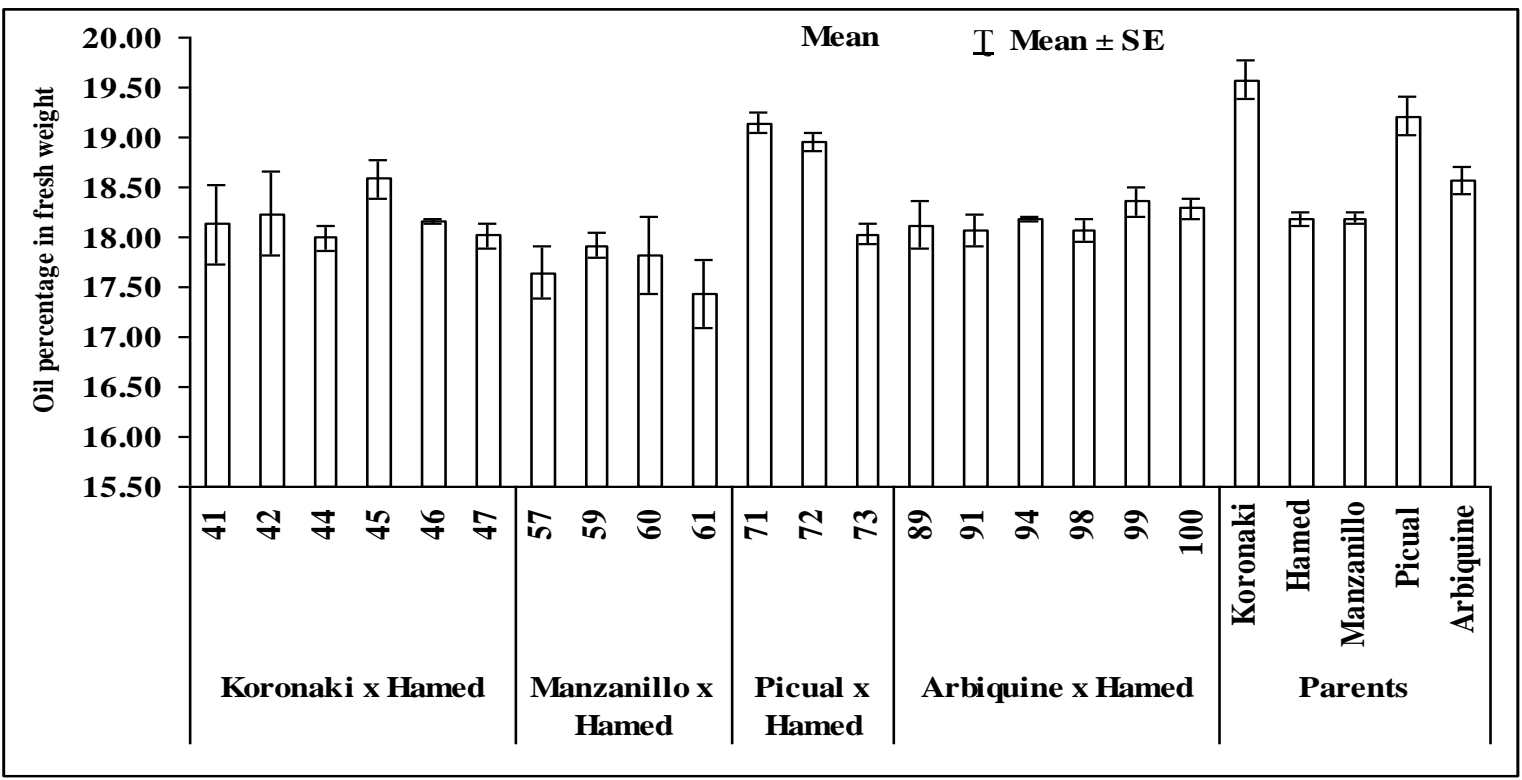

Fig, 21: Mean and standard error during three seasons for oil percentage in fresh weight of the olive progenies.
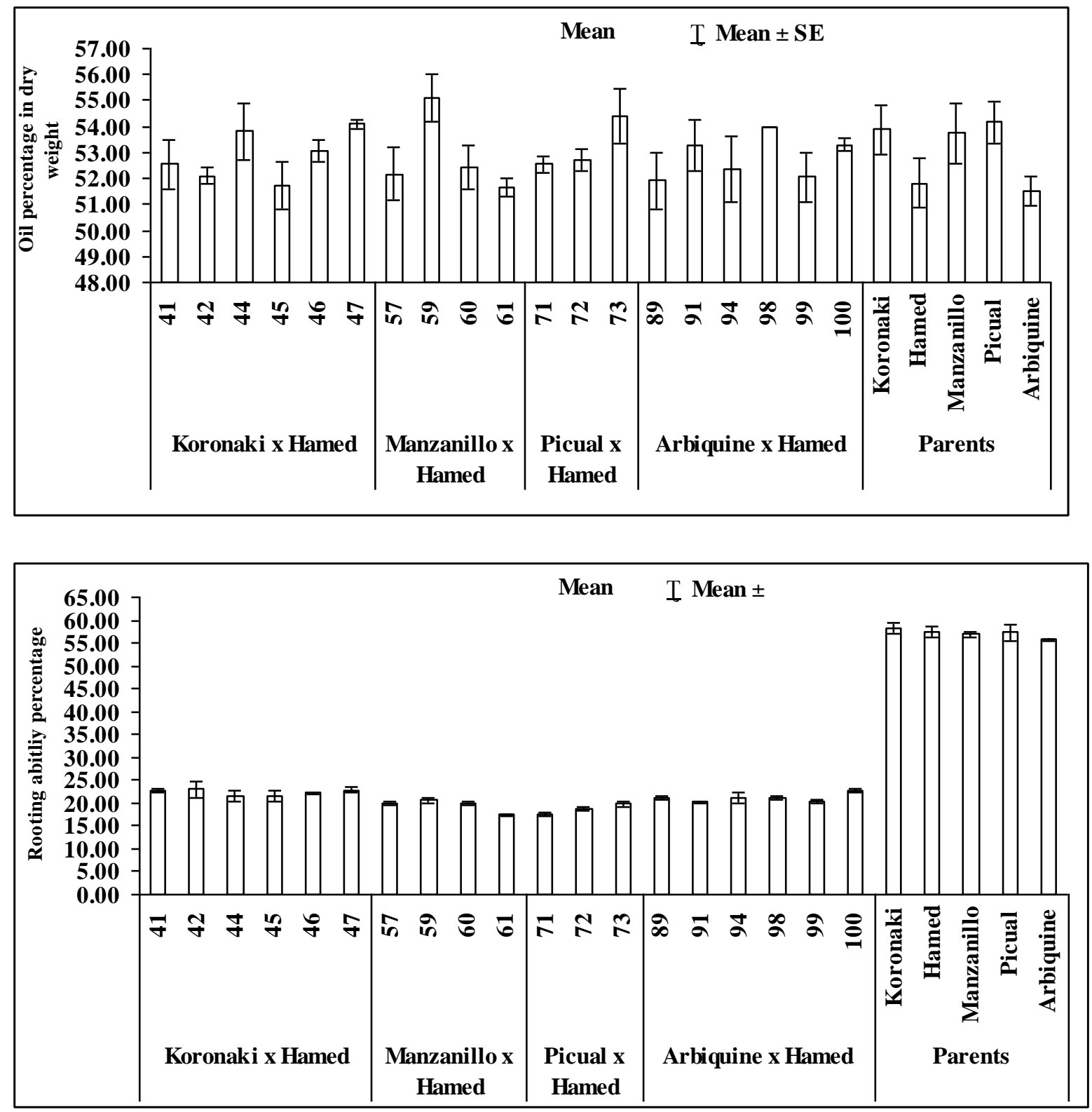

Fig, 23: Mean and standard error during three seasons for rooting ability percentage of the olive progenies. 


\begin{tabular}{|c|c|c|c|c|c|}
\hline \multirow[b]{2}{*}{ Progenies No } & \multicolumn{5}{|c|}{ Characteristics } \\
\hline & Productivity & $\begin{array}{c}\text { Constant } \\
\text { productivity }\end{array}$ & Fruit weight & Flesh/ stone & $\begin{array}{l}\text { Oil content } \\
\text { in dry weigh }\end{array}$ \\
\hline 41 & 31.63 & Constant & Medium & Low & High \\
\hline 42 & 31.13 & Constant & Medium & Low & High \\
\hline 44 & 30.13 & Constant & Medium & Low & High \\
\hline 45 & 32.00 & Alternate & Medium & Low & High \\
\hline 46 & 30.38 & Alternate & Medium & Low & High \\
\hline 47 & 31.38 & Constant & Medium & Low & High \\
\hline 57 & 30.00 & Constant & High & Medium & High \\
\hline 59 & 29.50 & Alternate & High & Medium & High \\
\hline 60 & 31.00 & Alternate & Medium & Low & High \\
\hline 61 & 30.63 & Constant & Medium & Low & High \\
\hline 71 & 32.00 & Alternate & Medium & Medium & High \\
\hline 72 & 32.13 & Alternate & Low & Low & High \\
\hline 73 & 29.38 & Constant & Medium & Low & High \\
\hline 89 & 30.75 & Alternate & Medium & Medium & High \\
\hline 91 & 30.50 & Constant & High & Low & High \\
\hline 94 & 29.88 & Constant & Medium & Low & High \\
\hline 98 & 29.88 & Constant & Medium & Medium & High \\
\hline 99 & 29.00 & Alternate & Medium & Medium & High \\
\hline 100 & 30.13 & Constant & High & Medium & High \\
\hline Koronaki & 35.25 & Alternate & Low & Low & High \\
\hline Hamd & 31.63 & Constant & High & Medium & High \\
\hline Picual & 31.13 & Alternate & High & Low & High \\
\hline Arbquine & 27.88 & Alternate & High & Medium & High \\
\hline Manzanello & 32.88 & Alternate & Low & Low & High \\
\hline
\end{tabular}

Thereon, the preferable, progenies are No. 73, 91 and 100 for table olive; progenies No. 42, 47, 71, 89 and 98 for oil and progenies No. 57 and 59 for dual purpose.

All the best selected progenies should be propagated and planted in three locations in order to evaluate their performance (i.e., tree growth, yield, fruit characteristics, oil content, oil compositions in fatty acids fruit compounds) in different geographical areas. It is a top priority to study qualitative and qualitative traits of olive production in more detail for the most interesting selections.

\section{References}

Alfei, B.; Paoletti, A.; Rosatai, Santineli A. and Panellig, A. (2008). Agronomic and qualitative evaluation of olive genotypes selected in central Italy. Adv. Hort. Sci., 22 (2): 136-144.

Arsel.H. and Cirik N. (1994). General overview of olive breeding in Turkey, Olivae, 52:25-27.

Ayton, J.; Mailer, R. J. and Robards, K. (2001). Changes in oil content and composition of developing olives in a selection of Australian cultivars. Australian Journal of Experimental Agricultural. 41: 815-821.

Barranco, D.; Cimato, A.; Fiorino, P.; Rallo. L.; Touzani, A.; Castaneda, C.; Serafini, F. and Trujillo Nvas, I.
(2000). World Catalogue of Olive Varieties. page 1522, publisher Olive Oil Council.

Bartolini, S. Andreini, L. Guerriero and R.; Gentili, M. (2006). Improvement of the quality of table olive in Tuscany through crossbreeding and selection: preliminary results of leccino $x$ konservolia hybrids. Olive bioteq. Second International seminar "Biotechnology and quality of olive tree products around the Mediterranean Basin Proceeding Vol.1:143-146.

Bellini., E. (1992). Behavior of some genetically characters in olive seedlings obtained by crossbreeding. Acta Horticultural 317: 197-208.

Bellini, E.; Parlati and M. V. and Pandolei, S. (1990). Response of crossed olive trees to seedling rooting. Atti XIII International Horticultural Congress Firenze, 26 ago- 1set. 3054 (Abstract).

Bellini, E. Giordani, E. and Rosati, A. (2008). Genetic improvement of olive from clonal selection to cross-breeding programs.Advances in Horticultural Science; 22(2):73-86.

Bellini E., Giordani, E., Parlati, M.V. and Pandofi, S. (2000). Three new olive cultivars obtained by crossbreeding. Acta Horticulturae, 586:221-223.

Bellini E., Giordani, E., Parlati, M.V. and Pandofi, S. (2002). Olive genetic improvement: thirty years of research. Acta Horticulturae, 586:105-108 
Corderio, A., (1997). Selection de cultivars tolerates. Tesis Doctoral. Universidad de Cordoba.

Cresti, M., Linskens, U., Mulcahy F., Muleahy, D.L., Bush, S., Distilio, J., XU, M. Y., Viguani, R. and Cimalo, A., (1997) Preliminary communication about the identification of DNA in leaves and olive of (olea europaea L.) Adv. Hort. Sci., 10:105-107.

Damijela Poljuha, Barbara Soladonja, Karolin Brkic Bubola and Maria Radulovic (2008). A multidisciplinary Approach to the characterization of Autochthonous Austrian olive (Olea europaea) varieties. Food. Technol. Biotechnol. 46 (4): 346-357

Del Rio, C. and Caballero, J. M. (1994). Preliminary agronomical characterization of 131 cultivars introduced in olive germplasm bank of Cordoba in March 1987. Acta Horticulturae 356:110-115.

Esmaeili, A. Shaykhmoradi, F. and Naseri, R. (2012). Comparison of oil content and fatty acid composition of native olive genotypes in different regions of Liam. International Journal of Agriculture and Crop Sciences (IJACS); 4(8):434-438.

Ferri, A., Padula. G., Giordani. F. and Billini, F. (2006). First observations on floral biology of advanced selections of olive obtained by crossing. Proceedings of the Second International Seminar Olivebioteq 2006. "Biotechnology and quality of olive tree produces around the Mediterranean basin". vol.1: $127-130$

Fontanazza G., Bartolozzi and Vergatig, F. (1998). Fs-17- Riv. Fruit., 5:61.

Hechmi, M. Raoudha, M. K. and Linda, B. Y. (2012). Distribution of some phenotypical characters within an olive population in Djebel Ouslet. American Journal of Plant Physiology; 7(3):104-119.

Lavee, S. (1990). Aims, methods and advances in breeding of new olive (Olea europaea L.) cultivars. Acta Horticulturae 286, 23-36.

Lavee S., Avidn B. and Meni Y. (2003). "Askal" a new high performing oil variety for intensive and superintensive olive orchards Olivae, 97: 53-59.

Lavee, S., Haskal A. and Vodner. M. (1986). "Barnea" a new olive cultivar for oil extraction resistant to Spilocaea Oleagina. Acta Horticulturae 474: 125-128.

Lavee, S., N. Avidan, A. Haskal and A. Ogrodovich (1996). Juvenility period reduction in olive seedlings-a tool for enhancement of breeding. Olivae 60: $33-41$.

Lavee S., Avidan B., Meni Y., Kaskala and Wodner, M. (2004). Three new varieties of semi-dwarf table olives- Olivae 102: 33-41.
Lavee. S., Harshemesh H., Haskal A., Avidan B., Grodovich A., Avidan N. and Trapero, A. (1999). Maalot a new cultivar for oil extraction resistance to spilocaea oleagina. Acta. Horticulturae, 474: $125-128$.

Leon L., De La Rosa R., Barranco D. and Rallo, L. (2006). Agronomic characterization of 15 selections of the olive cross breeding program of Cordoba, Spain. proceedings of the Second International Seminar olivebioteq. "Biotechnology and quality of olive tree produces around the Mediterranean basin" . vol.1:87-93.

Medina, E. Morales-Sillero, A. Ramirez, E. M. Rallo, P. Brenes, M. Romero, C. (2012). New genotypes of table olives: profile of bioactive compounds. International Journal of Food Science \& Technology; 47(11):2334-2341.

Muzzalupo, I. and Perri, E. (2009). Genetic diversity in olive tree cultivars from Italy and other countries of the Mediterranean basin as revealed by RAPD and SSR molecular marker. Advances in Horticultural Science; 23(4):263-275.

Pannelli, G.; Rosati, A.; Pandolfi., S, Padula, G., Mennone, C.; Giordani, E. and Bellini, E. (2006). Field evaluation of olive selections derived from a breeding program. olivebioleq. Proceeding of the Second International Seminar "Biotechnology and quality of olive tree products around the Mediterranean Basin. Vol. 1:.95-102.

Pritsa, T. S., Voyiatzis, D.G., Voyiatzis, C.J. and Sotiriou, M.S. (2003). Evaluation of vegetative growth traits and their relation to time to first flowering of olive seedlings. Australian Journal of Agriculture Research 54, 371-376.

Rallo, (1995). Selection and breeding of olive in Spain. Olivae, 59: 46-53.

Saad El-Din, Ikram, E.G. Mikhail and I.M.S. Osman (2009). Evaluation of some olive hybrids derived from a breeding program. J. Agric., Sci. Mansoura Univ., 34(7):8111-8128.

Sampaio, E. M. and Pinheiro, A. C. (2012). VI International Symposium on Olive Growing, Evora, Portugal. Acta Horticulturae; (949):27-600.

Santos Antunes A F., Mohedo A., Trujillo I. and Rallo, L. (1999). Influence of the genitors on the flowering of olive seedlings under forced growth. Acta Horticulturae, $474: 103-105$.

Sonnoli, L., Sonnoli A., Sonnoli S. and Sonnoli, E. (2003). CSS Diana-Plant Varieties Journal, 16 (2): 61.

Trigui, A. (1996). Improving the quantity and quality of olive production in Tunisia. Olivae. 61: 34-40. 


\section{سلوك بعض هجن الزيتون الناتجة من برنامج التحسين الوراثى \\ عماد جرجس ميخائيل}

قسم بحوث الزيتون وفاكهة المناطق شبه الجافة - معهد بحوث البساتين - مركز البحوث الزراعية

الزيتون من أهم الدحاصيل الزيتية فى حوض البحر الأبيض الكتوسط لزيادة الطلب على الزيت والأصناف الجديدة من الزينون

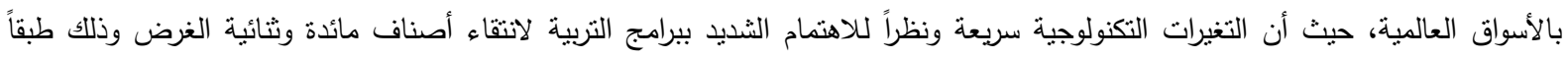
لبرنامج التحسين الوراثى فى مصر سنة 1994.

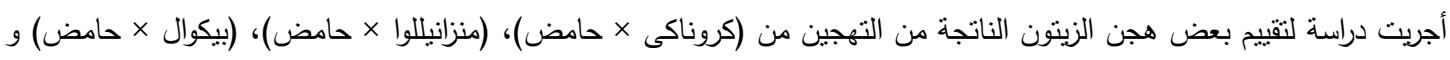

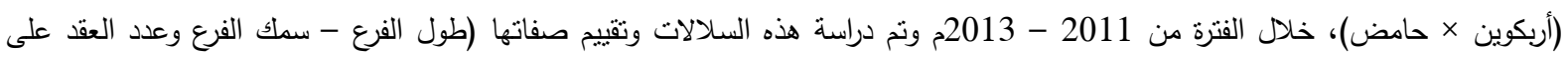

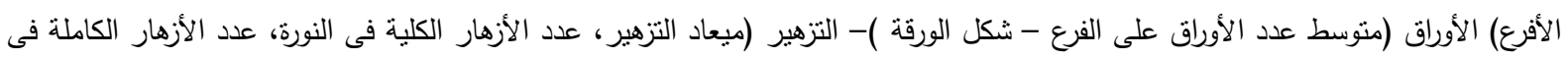

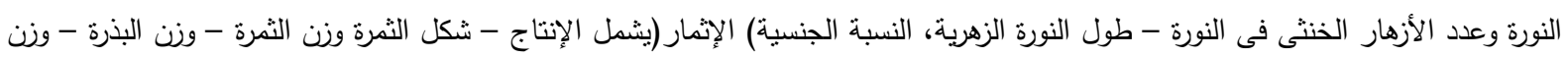
اللحم - وزن اللحم/البذرة) - والقدرة على التجذير . للقدرة

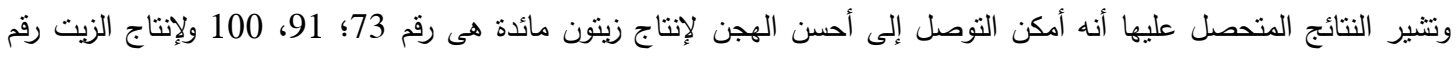

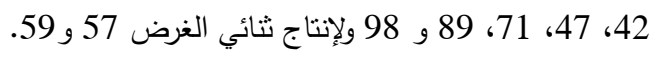

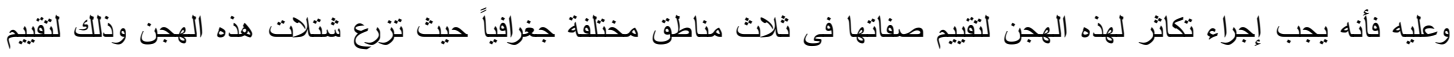

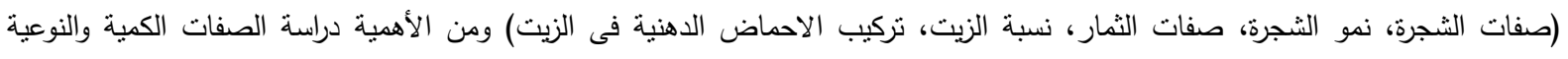

للإنتناج اكثر تفصيلا للهجن الاكثر تميزا . 